\title{
Reservoir Formation Damage; Reasons and Mitigation: A Case Study of the Cambrian-Ordovician Nubian ' $C$ ' Sandstone Gas and Oil Reservoir from the Gulf of Suez Rift Basin
}

\author{
Ahmed E. Radwan ${ }^{1,2}$ (D) David A. Wood ${ }^{3}(1) \cdot$ A. M. Abudeif ${ }^{4} \cdot$ M. M. Attia ${ }^{4} \cdot$ M. Mahmoud ${ }^{5} \cdot$ Ahmed A. Kassem $^{2}$. \\ Maciej Kania' ${ }^{1}$
}

Received: 13 September 2020 / Accepted: 14 July 2021 / Published online: 17 August 2021

(c) The Author(s) 2021

\begin{abstract}
Reservoir formation damage is a major problem that the oil and gas industry has to mitigate in order to maintain the oil and gas supply. A case study is presented that identifies the impacts of formation damage and their causes in the Nubian 'C' hydrocarbon reservoir within Sidki field located in the Southern Gulf of Suez, Egypt. In addition, a formation damage mitigation program was designed and implemented involving an effective stimulation treatment for each well experiencing reservoir damage. The data available for this study include core analysis to provide rock mineralogy and lithology; analysis of production fluid data; water chemistry; drilling fluid composition; perforations and well completion details; workover operations; and stimulation history. The diagnosis of formation damage based on the integrated assessment of the available data is associated with several benefits, (1) The integration of the data available helps provide a robust analysis of formation damage causes and in establishing suitable remediation actions, (2) Workover fluid is confirmed as the primary cause of reservoir damage in the studied well, (3) Several reservoir damage mechanisms were identified including water blockage, solids and filtrate invasion, fluid/rock interaction (deflocculation of kaolinite clay), salinity shock and/or high-sulfate content of the invaded fluid, (4) Irrespective of the potential causes of formation damage, the primary objective of a gas production company is to mitigate its effects and the integrated dataset helps to design appropriate and effective stimulation treatments to overcome formation damage, and (5) In gas reservoirs, especially low permeability ones, extra precautions are necessary to avoid potential reservoir damage due to workover fluid invasion.
\end{abstract}

Keywords Reservoir damage analysis · Formation damage $\cdot$ Reservoir damage reasons $\cdot$ Reservoir damage mitigation Nubia sandstone reservoir · Gas reservoir · Workover Formation damage · Fines migration · Well stimulation · Fluid invasion · Water blockage $\cdot$ Overbalanced workover $\cdot$ Integrtaed formation damage assesment workflow

\section{Introduction}

Formation or reservoir damage is a challenging issue in oil and gas industry that can substantially reduce fluid flow rates and recovery from subsurface reservoirs [1-6]. It typically involves the reduction in the near-wellbore permeability leading to a reduction in the well productivity. It is a relatively frequent outcome of operations conducted on wellbores during drilling, workover, production, stimulation programs and/or other actions designed to enhance gas or oil recovery (EOR) [3-10]. Many authors have investigated the potential causes of formation damage, and a number of distinct potential causes have been identified in relation to the various downhole activities carried out in gas and oil boreholes [ex 3, 4, 6, 11-30]. Reservoir damage involves 
complicated phenomena, frequently resulting from the interactions of several mechanisms. As well, Damage to the formation can be classified as either induced or naturally occurring (Fig. 1) [3]. These mechanisms can be usefully classified more broadly in terms of their underlying biological, chemical, mechanical and thermal causes $[3,4,6,31]$. Formation damage can happen anytime and anywhere, and in many cases, the information available makes it difficult to quantify $[3,4,6,8,18,21,32]$. Reservoir damage can occur during drilling [e.g., 29, 33], during workovers [e.g., $6,21,34]$, and/or during secondary and tertiary recovery techniques [3-6, 8, 31]. One or more of these mechanisms can contribute to the resulting formation damage in a specific reservoir. Understanding the mechanisms of reservoir damage and the factors controlling its severity are crucial for determining and quantifying its impacts on gas and oil production efficiency [1-4, 6, 8, 11, 21, 35]. Reservoir damage diagnosis is vital for achieving effective EOR development programs for oil and gas reservoirs, where the information gained can be used in planning future wells operations with proactive prevention of formation damage in mind. [3, 4, 6 , $9,10]$. Formation damage type and severity can be analyzed using the available data and monitoring and remediation techniques implemented to minimize its impacts $[6,8,36]$.

However, there is no unified system that accurately quantifies the type of damage, its location and extent in the reservoir beyond the wellbore, its causes and effects on well productivity or injectivity. This means that the design of appropriate stimulation treatments for each well typically has to be tailored to the conditions encountered and observed in a specific reservoir. The integration of reservoir engineering and geological data can grant valuable insights into the natural formation rock interaction with treating fluids [e.g., $3,4,6,37]$. In the case study presented, we provide analysis of formation damage recorded in the Nubian ' $\mathrm{C}$ ' reservoir of the Sidki field located in the southern Gulf of Suez (Egypt). Severe formation damage problems were recorded as the outcome of a workover operation conducted in the Sidki$\mathrm{X} 1$ well. In order to diagnose the reservoir damage in the Nubian ' $C$ ' reservoir in the Sidki-X1 well, a comprehensive workflow is applied that integrates production, geological, and reservoir engineering data [3-6].

The objectives of this paper are to: (1) introduce and define a consistent, multi-disciplinary workflow to help in the investigation and recognition of formation damage mechanisms in oil and gas reservoirs; (2) document formation damage diagnosis applying the workflow to a case study that could be used as a reference for similar cases; (3) define the root causes of formation damage in a sandstone reservoir using a producing gas and oil field example; (4) detect potential pitfalls associated with commonly applied operational well treatments; (5) define the best practices for dealing with gas reservoirs so as to prevent formation damage occurring during various well operations, and this involves linking potential formation damage outcomes to underlying geological factors and the designs of well operations; (6) help reservoir engineers to more comprehensively diagnose reservoir damage and thereby avoid some common operational and well-design pitfalls; and (7) highlight the mitigation and remediation alternatives for gas reservoirs.

\section{Geological and Structural Setting}

The Gulf of Suez basin, and its gas and oil potential, have been extensively studied [e.g., 3-6, 38-61]. The Sidki field was discovered in 1976, it is a field that has produced oil and
Fig. 1 Formation damage causes classified in terms of induced or natural after $[3,6]$

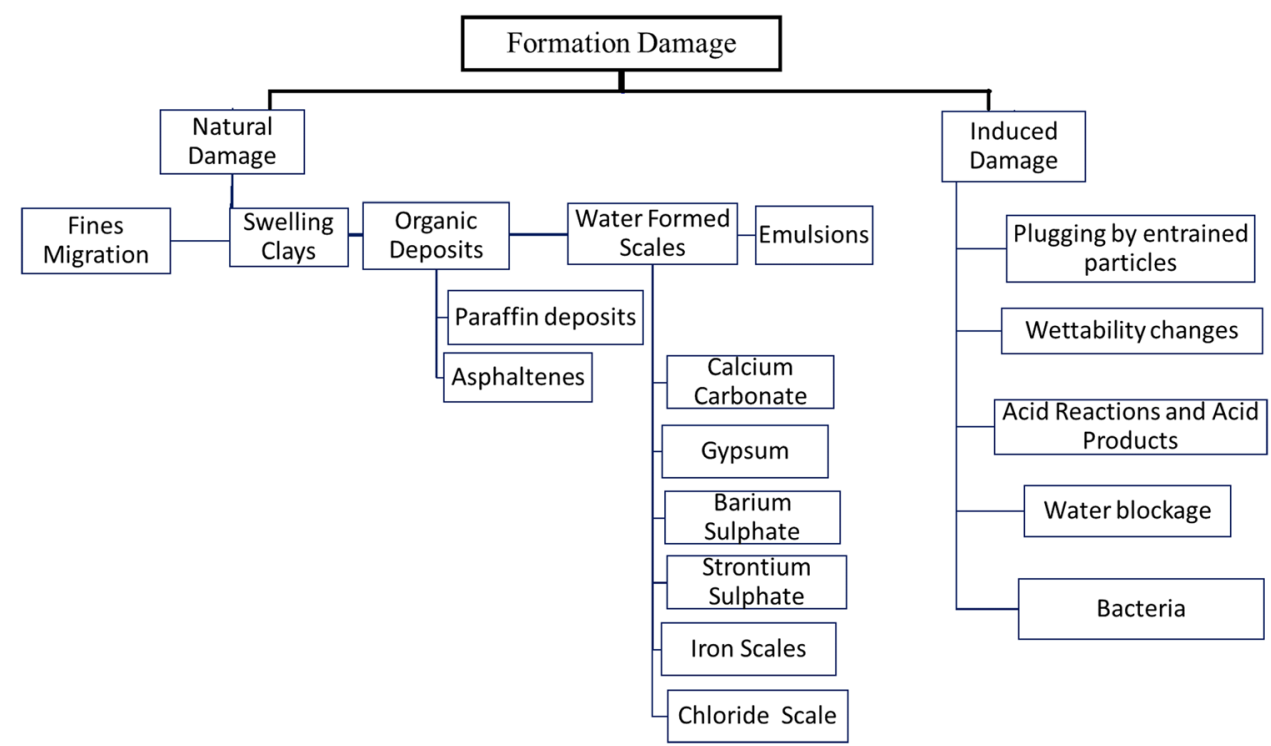


gas in the southern Gulf of Suez (offshore Egypt). Figure 2 shows the Sidki field and the studied Sidki-X1 well location.

The oil accumulations were located in the Nubian ' $\mathrm{C}$ ' sandstone reservoirs of Cambrian-Ordovician age, and a secondary gas cap developed during the oil production phase $[62,63]$. Nine producing wells were drilled from platform 'A' between discovery date and 1988. Eight of those wells produced oil from the Nubian ' $\mathrm{C}$ ' reservoir. Additionally, one well produced from overlying Miocene sediments. Platform 'A' was struck by a cargo ship causing complete shutdown. In 1993, a new platform 'B' was installed $1 \mathrm{~km}$ away from the previous platform ' $A$ '. Eight producing wells were drilled from platform "B" up to the end of 1996. Three oil-producing wells were converted to injectors to initiate secondary recovery. Secondary recovery in the field aimed to boost reservoir pressure and minimize gas cusping from the large gas cap. The original oil-in-place in the field was 295 million barrels of oil (MMBO). Following secondary recovery, the field had produced $81 \mathrm{MMBO}$ and 0.5 Billion of standard cubic feet of gas (BCF) by the end of 2016, achieving a total recovery factor of $27 \%$ up to that point in time.

Figure 3 displays a generalized (southwest-northeast) cross-section traversing the northern section of the Sidki Field that includes the Sidki-X1 well location [62]. This reveals the rotated fault-block structural configuration of
Fig. 2 Location map showing the Sidki-X1 well location within the Sidki field

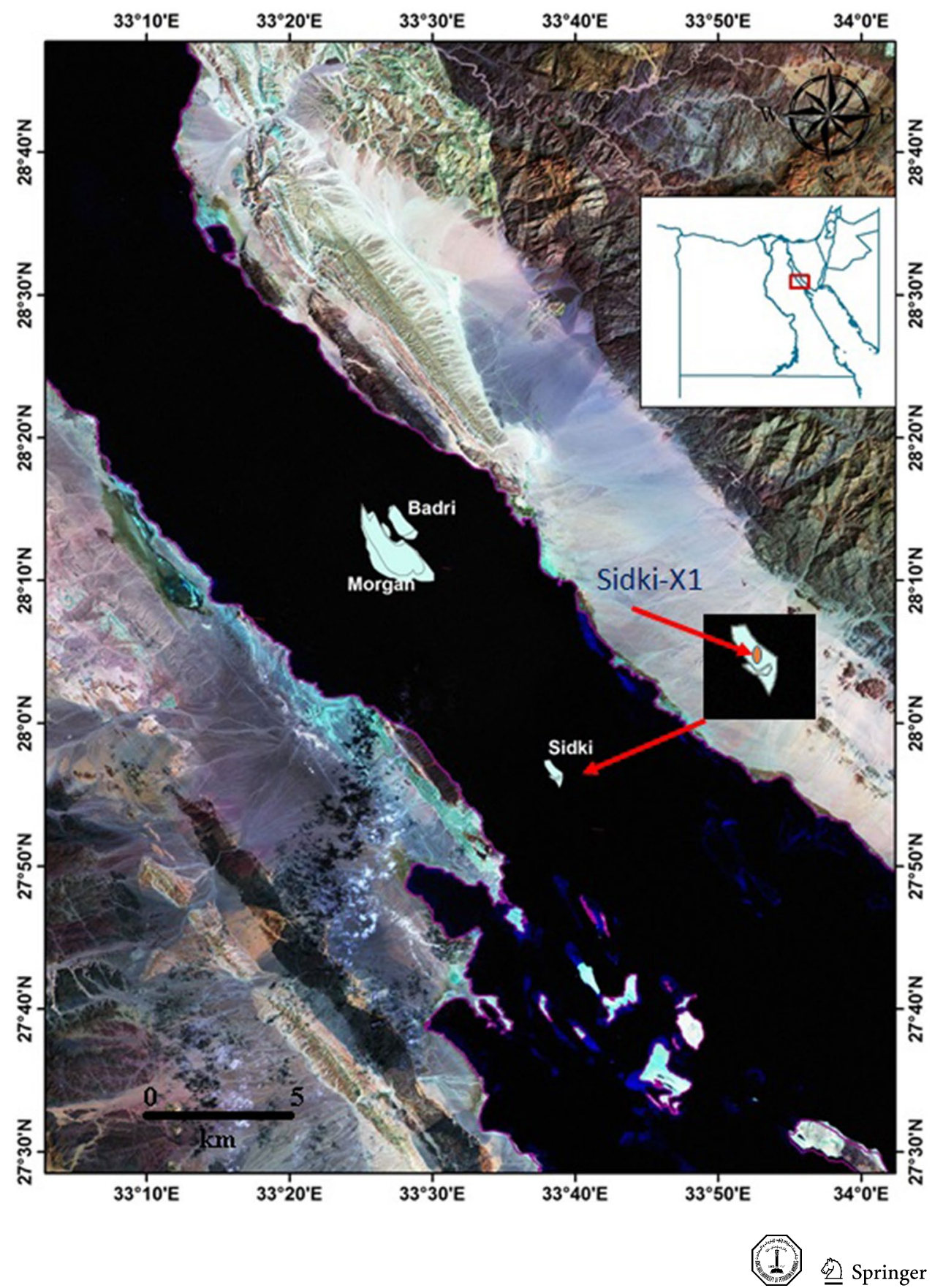




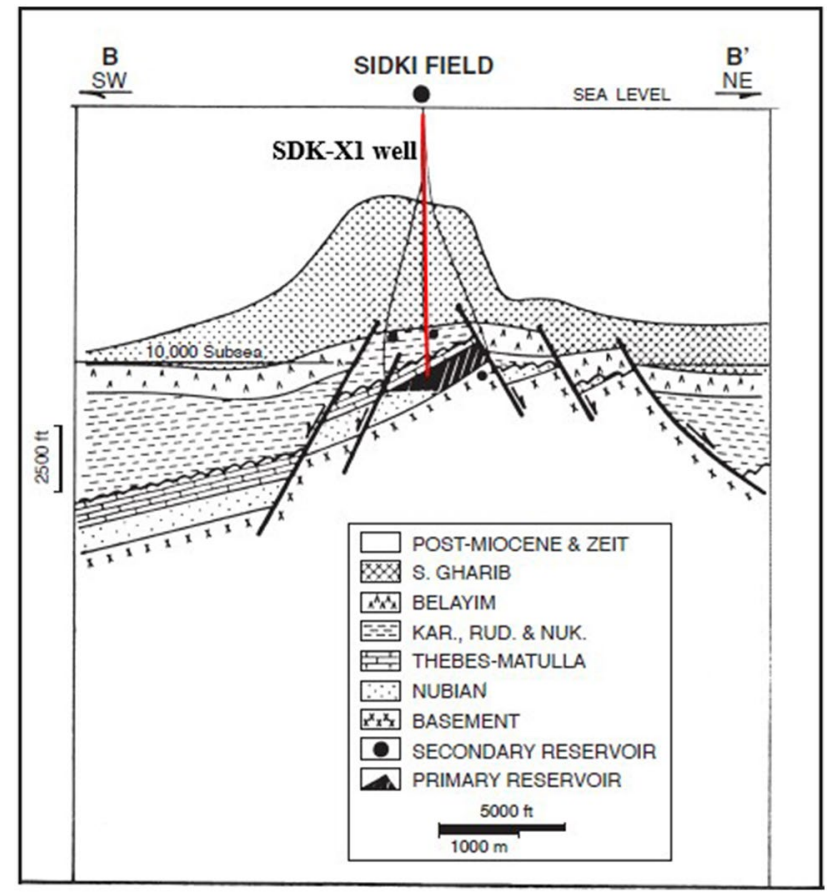

Fig. 3 Southwest to northeast cross-section of the Sidki Field, showing the Sidki-X1 well trajectory, Modified after [64].

the field's trap. The Sidki Field is located in an extensional structure defined by northwest and northeast trending faults. It is trapped within a steeply dipping (28-32 degrees) tilted, northwest-trending fault block. The field is bounded to the northeast by a large normal fault, with downthrow displacements of up to 1300 feet and dips of greater than 60 degrees toward the northeast [62-64].

Figure 4 shows a generalized stratigraphic column of Sidki field. It is subdivided into Nubian A, B, C, and D units based on paleontology data $[44,65]$. The Nubian ' $C$ ' sandstones are primarily composed of quartz arenite according to accepted sandstone classifications [66-68]. It is moderately sorted and varying from medium to coarse grained. The reservoir zone of interest for formation damage analysis is the main producer Nubian ' $\mathrm{C}$ ' unit.

\section{Materials and Methods}

The geological evaluation performed for this study is based on petrographic, thin-section and X-ray diffraction (XRD) analysis. The reservoir engineering evaluation performed for this study is based on the analysis of drilling fluids, reservoir fluids, completion fluids, water injection fluids, cementing programs, and stimulation history. Additional well information, reservoir data and production history are used to

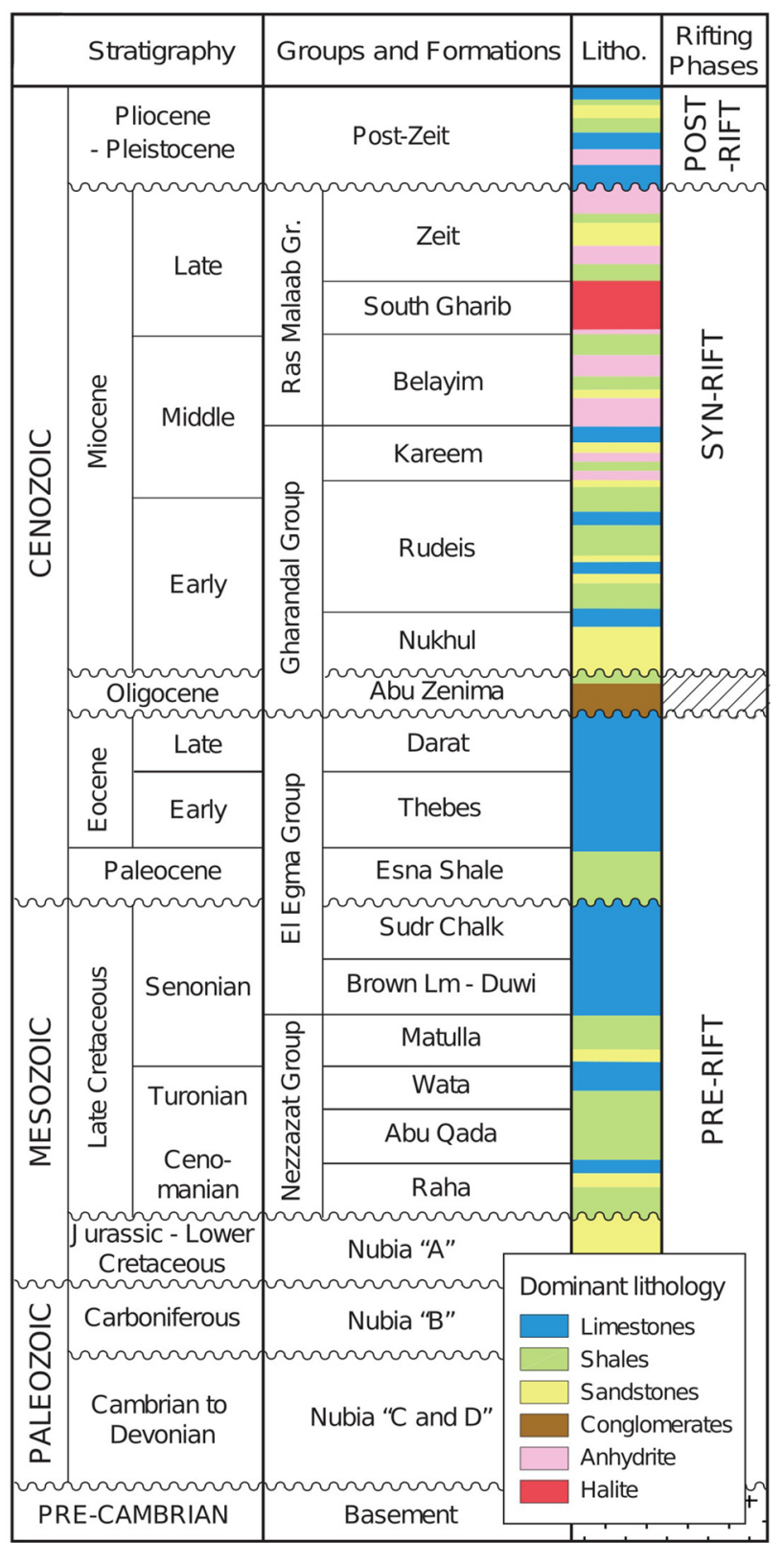

Fig. 4 Stratigraphic column of southern Gulf of Suez, modified after $[44,56,65]$

quantify the formation damage in well Sidki-X1 over time. Based on the newly developed reservoir damage analysis workflow introduced by Radwan et al. [3, 4] and Radwan [6], additional well information, reservoir data, and production history are used to quantify the formation damage in well Sidki-X1 over time. All available geological reports, mud logs and electrical wireline logs were also integrated into the analysis of the Nubian ' $\mathrm{C}$ ' sandstone reservoir unit penetrated by the Sidki-X1 well. 


\subsection{Geological Data}

\subsubsection{Rock Sample Descriptions}

Detailed descriptions of core samples and ditch cuttings have helped to accurately define formation damage in the zone of interest. A one hundred and fifty feet long section was cored through the reservoir (depth interval 10850-11000ft). These cores are of high integrity and are maintained in their recovered form. This has made it possible to determine variations in grain size, cementation and to record the presence of sedimentary structural features with confidence.

\subsubsection{Thin-Section Petrography}

Petrographic description was recorded for 28 polished thin sections taken from various points along the rock cores. These descriptions have recorded variations in the mineralogy, porosity and cementation within this reservoir and identified the presence of certain accessory minerals.

\subsubsection{Scanning Electron Microscopy (SEM) and XRD Analysis}

SEM analysis was performed on selected samples taken from the rock cores to detect and differentiate between allogenic and authigenic clays. XRD analysis was conducted to determine the detailed mineralogical makeup of the sandstones. Clay minerals were analyzed on particle sizes as small as 5 microns.

\subsubsection{Petrophysical Evaluation}

The petrographic information obtained from the rock samples was taken into consideration as part of the wireline well log data analysis, because such data are known to be sensitive to mineralogical as well as fluid influences [40-43, 69-71]. Porosity and permeability that obtained from core samples were used to conduct formation analysis on the available Sidki-X1 well log data and help to further establish the reservoir characteristics. Also, the well logs were used to distinguish different characteristics include lithology, thickness and fluid types. The available wireline logs are gamma ray, sonic (compressional velocity), shallow and deep resistivity, neutron porosity, and bulk density logs recorded across the depth interval $10800 \mathrm{ft}$ to $11400 \mathrm{ft}$. Resistivity readings in the offset Sidki field wells reached more than $500 \Omega$-meter.

\subsection{Reservoir Engineering Data}

All dynamic data relating to the Nubian reservoir were collected and assessed. Reservoir parameters and historical datasets of well operations were compiled and evaluated. Well production histories provided insight to reservoir behavior over time. Perforation intervals and the nature of workover operations conducted on specific producing zones were clarified. Rock samples and cores were reevaluated to confirm reservoir properties. Fluid properties, including reservoir fluids and operational fluids (injection and kill fluids), were investigated to define differences and similarities between them, and to identify potential effects they could have on the reservoir over time.

\subsection{Workflow Applied to Delineate Formation Damage In Nubian ' $C$ ' reservoir}

An established workflow (Fig. 5) that integrates the data recorded from the various analysis conducted (Sects. 3.1-3.5) was applied to delineate and quantify the nature of formation damage in the Nubian ' $\mathrm{C}$ ' reservoir penetrated by the Sidki-X1 well. The workflow is mainly based on the developed formation damage workflow by Radwan et al. [3-6].

This integrated workflow involves the following sequential steps:

- Comprehensive data collection and categorization. All available data need to be compiled, categorized and, in some cases, preprocessed before it can be meaningfully analyzed. The higher the resolution, variety and quantity of the data available, the more reliable the analysis and interpretation can be.

- Initial data analysis of the individual data components should lead to realistic delineation and quantification of the extent of formation damage. This, in turn, should narrow down the possible diagnosis of the causes of that formation damage. Also, it should help to provisionally indicate appropriate mitigation operations required and the fluids selections appropriate for such remedial actions.

- Integration of the geological, petrophysical and engineering datasets typically helps to further refine the feasible diagnosis of formation damage in the reservoir studied.

- Results of the integrated dataset analysis should precisely define the nature of the formation damage impacting the reservoir zone of interest and establish suitable recommendations for avoiding or mitigating that formation damage in future and existing wells, respectively.

Laboratory compatibility tests of fluid wash or injection treatments for specific reservoirs are often required to distinguish the pros and cons of each potential formation damage mitigation alternative identified. These reservoir formation, reservoir fluid and injection fluid compatibility tests help to identify the fluid-treatment designs that are 


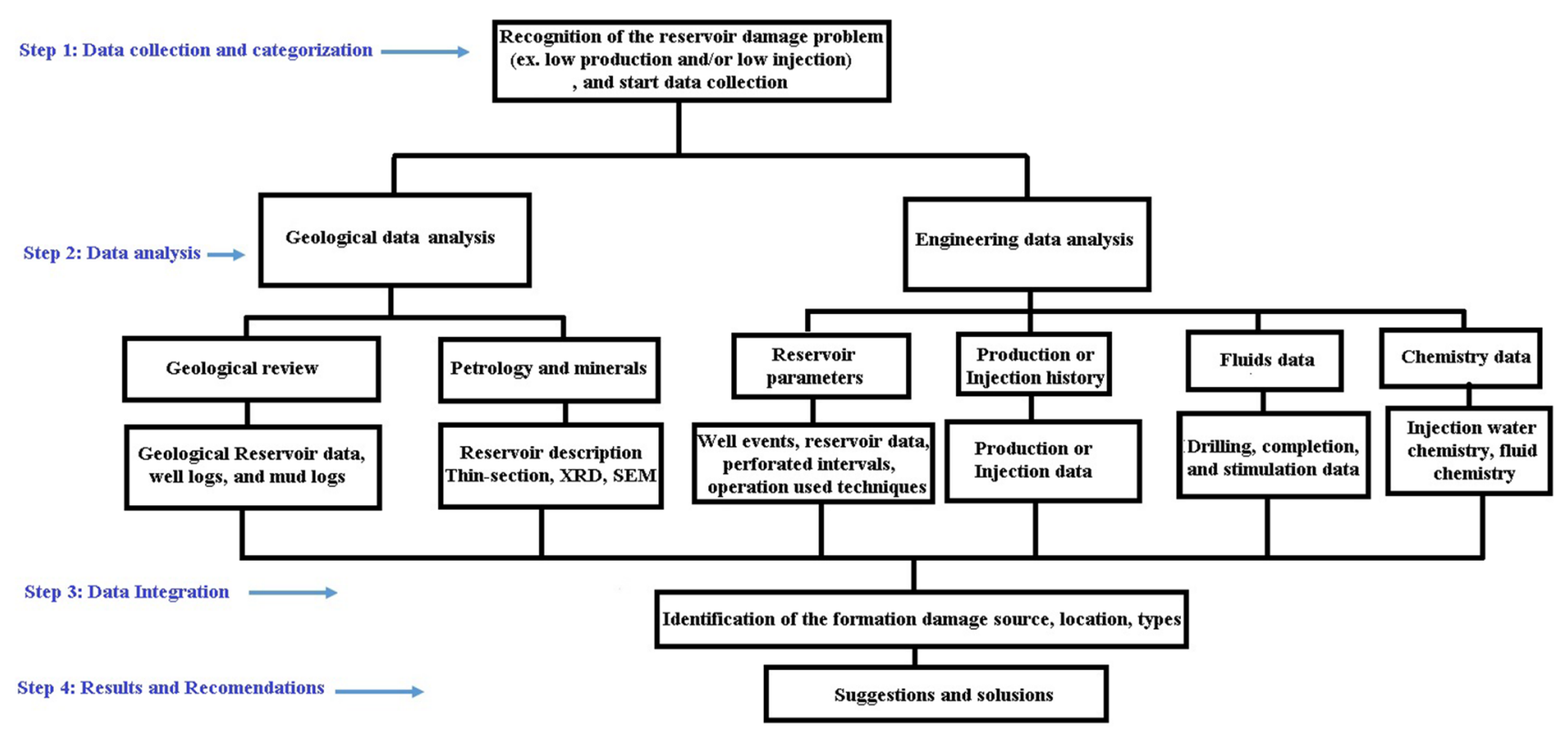

Fig. 5 Formation damage wellbore analysis workflow, modified after Radwan et al. [3]

Table 1 Specific types of reservoir formation damage commonly associated with workover operation, factors influencing it impacts and how it is typically addressed

\begin{tabular}{lll}
\hline Causes of formation damage & Accelerating factors & How to cure the damages \\
\hline Residual cement plugging & Operate at overbalanced conditions & Acid stimulation \\
$\begin{array}{l}\text { Plugging of wireline loosened iron } \\
\text { scale or paraffin from tubing }\end{array}$ & $\begin{array}{l}\text { High-permeability formation } \\
\text { Large variation in permeability }\end{array}$ & Customized chemical treatment \\
$\begin{array}{l}\text { Plugging by metallic particle } \\
\text { resulting from casting repair }\end{array}$ & Uncleaned wellbore use of corrosion inhibitors or emulsion breakers & \\
operations & & \\
Damaging workover fluids & & \\
Damaging bridging materials & & \\
\hline
\end{tabular}

most likely to be effective. The treating chemicals most often used to combat or overcome formation damage fall into four categories: (1) solvents; (2) oxidizers; (3) scale removers; and (4) acids. These fluid types can be used individually or in sequence, in various combinations, to combat the different types of formation damage $[3,4,6$, 32]. Table 1 identifies how well workover operations can specifically create formation damage issues, some of the factors that exacerbate such formation damage and remediations methods typically used to address that damage.

\section{Results}

Following step 1 (data collection and categorization), the initial data analysis step 2 of the adopted workflow is divided into several separate components of geological data analysis and reservoir engineering and fluid analysis.

\subsection{Analysis of Geological Data}

Geological data analysis is subdivided into (1) comprehensive geological characterization of the Sidki gas and oil field; (2) facies analysis, mineralogy, and petrography of the entire Nubian ' $C$ ' reservoir penetrated by the Sidki-X1 well; and (3) petrophysical characteristics. These components provide a provisional analysis of formation damage for the Nubian ' $\mathrm{C}$ ' reservoir at the Sidki-X1 well location.

\subsubsection{Geological Characterization of the Nubian ' $C$ ' Reservoir}

The Gulf of Suez is rich in oil and gas fields [50-59, 72-75], and the Sidki is located in the southern part of the basin, close to significant oil and gas fields. The geological description of the Sidki field presented in Sect. 2 summarizes this analysis. From the Sidki-X2/X3/X4 wells available, further details can be established. Lithology and sedimentology 
Fig. 6 Complete set of basic wireline logs recorded for the Sidki-X1 well at the time it was drilled. The effective porosity and perforation intervals for Nubian ' $C$ ' reservoir are also displayed

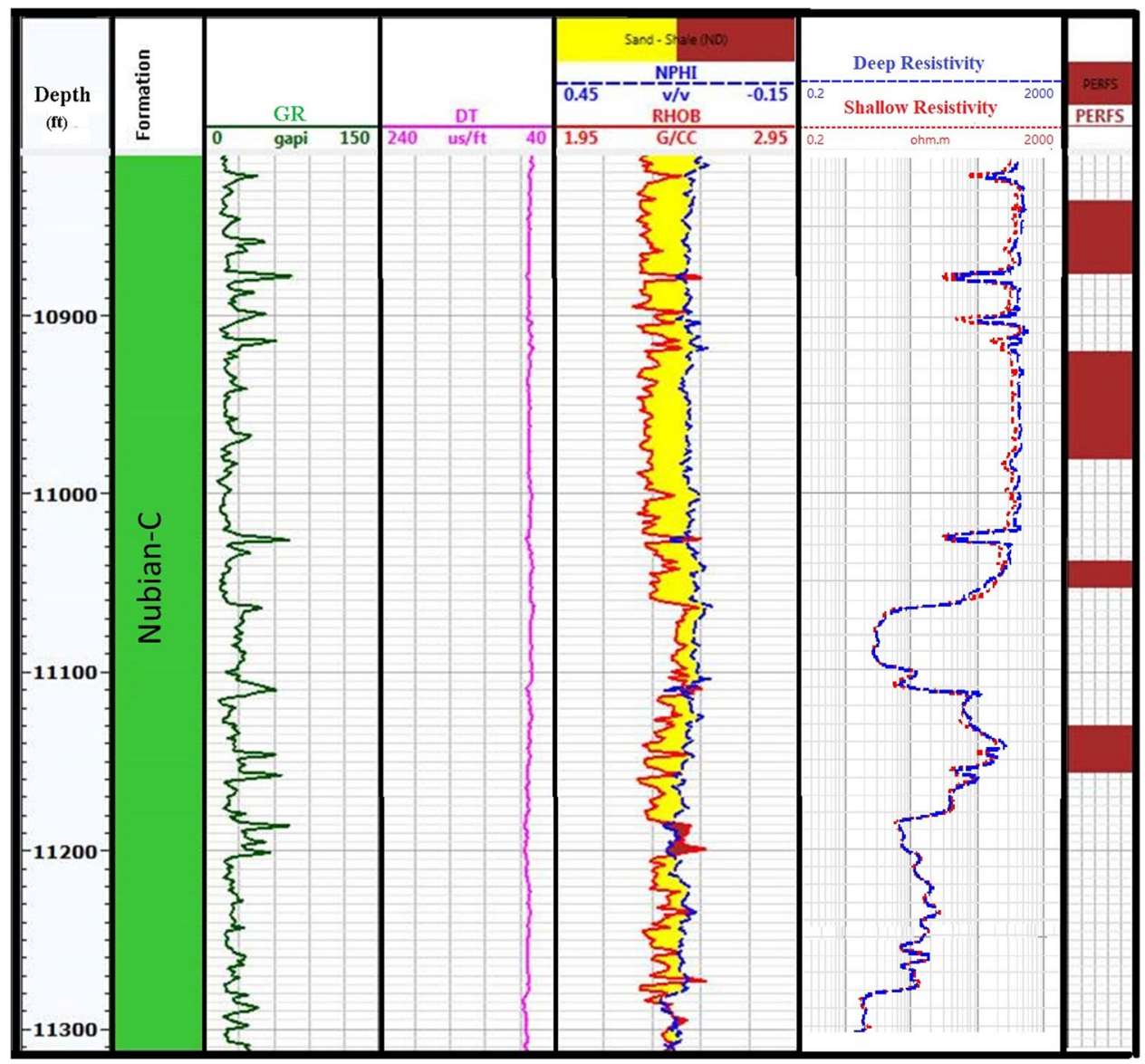

analysis of the Nubian 'C' Sandstone within Sidki-X1 well indicate that it is a mature sediment deposited in a shallow marine to continental /fluvial settings. The Nubian ' $C$ ' reservoir (Fig. 6) varies in thickness across the field with average gross reservoir thickness of $850 \mathrm{ft}$. The net/gross ratio for that reservoir based on a porosity threshold of $13 \%$ varies from 0.8 to 1 . The pore shapes in thin sections display both connected and non-connected pores. Pores consist predominantly of primary intergranular porosity that formed during deposition, and inter-crystalline micro-porosity between pore-filling kaolinite crystals. These features are consistent across the entire field. The Nubian ' $C$ ' reservoir in the Sidki field is impacted by numerous natural fractures and microfaults. The reservoir zones surrounding these features tend to display reduced permeabilities. Water saturation averages $20 \%$ and ranges between 5 and $100 \%$ for theSidki-X1 well based on well $\log$ analysis. Diagenetic features that characterize the Nubian sandstones in Sidki field encompasses post compaction cementation, aggrading recrystallization, pressure solution effects, corrosion and partial replacement, and development of authigenic clays, particularly kaolinite, illite and chlorite. Several regional studies have described the diagenetic processes impacting the Nubian sandstones in the Gulf of Suez, Sinai and Eastern Desert basins [76-80].
The reservoir displays heterogeneous diagenetic effects on its pore network on a regional scale.

Figure 6 illustrates the complete set of basic wireline logs recorded for Sidki-X1 well across the Nubian ' $C$ ' reservoir. The first column displays the measured reference depth in feet. The second column confirms that the logged interval displayed all belongs to the Nubian ' $C$ ' zone. The remaining columns display the basic suite of well logs and perforation intervals. Qualitative inspection of this information helps to further characterize the Nubian ' $\mathrm{C}$ ' reservoir. For instance, it is clear from the gamma-ray curve (Fig. 6) that cleaner and more massive sandstone intervals make up the upper portion of the Nubian ' $C$ ' reservoir penetrated by the Sidki-X1 well.

\subsubsection{Facies Analysis, Mineralogy, and Petrography}

The Nubian ' $C$ ' sandstone reservoir consists mainly of quartz arenites with some clays and thin shale interbeds [78, 81-83]. Thin-section and SEM analysis has identified occurrences and distributions of clays, feldspars, carbonates, and other minerals within the Nubian ' $C$ ' reservoir in the Sidki$\mathrm{X} 1$ well. XRD mineralogical analysis from four example depths in the core samples are displayed in (Fig. 7). These analyses reveal a high concentration of kaolinite (15-18\%) 


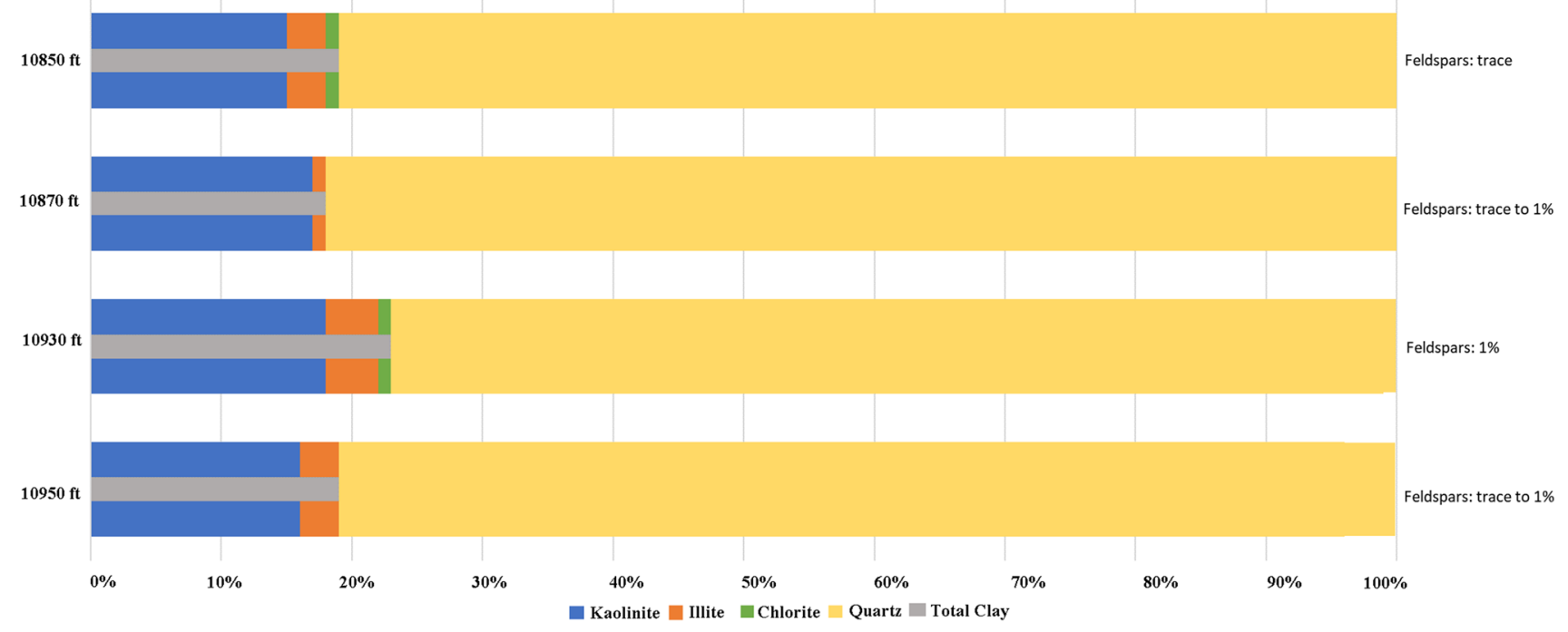

Fig. 7 Mineral Percentages in representative samples from Nubian 'C' cores in the Sidki-X1 well analyzed by XRD

accompanying the dominant quartz component (76-81\%). Other clay minerals, specifically illite (3-5\%) and chlorite (traces to $1 \%$ ), are also present.

These formation characteristics confirm that the Nubian ' $\mathrm{C}$ ' sandstone reservoir penetrated by the Sidki-X1 well is consistent with the general features of the Nubian ' $C$ ' reservoir in the Sidki field as a whole $[65,84]$, and regional findings [78]. The quartz arenite sandstone and extensive kaolinization observed in the Sidki field Nubia ' $C$ ' reservoir have also been recorded in October, July and Ramadan fields (central and south central Gulf of Suez) [84-87]. Although kaolinite is a non-swelling clay, being present in high concentrations means that it is relatively easily mobilized by fluid flow as fines and, as such, can cause formation damage by blocking pore throats.

Figure 8 shows photomicrographs of Nubian ' $C$ ' sandstone thin sections from selected depths in the Sidki-X1 well. At a high level, these images reveal the microscopic fabric and texture of the sandstones, their visual porosity and accessory minerals. In addition, they show quartz grains varying from medium to coarse-grained sizes, assembled as well sorted sub-angular grains. Some sandstones are bound by silica cement, silica overgrowths, authigenic clays dominated by kaolinite but including illite and chlorite, and, rarely, calcite cement. These cements were for the most part formed during burial by acid-water flushing and clay transformation acting to reduce the porosity and permeability of the sandstone [88-91]. Moreover, authigenic kaolinite and amorphous organic matter is visible in some samples. In detail, Fig. 8 a $(10,870 \mathrm{ft})$ represents a moderately sorted, medium-grained quartz arenite. Figure $8 \mathrm{~b}$ (10850ft) represents a coarse-grained, poorly sorted, sub-rounded quartz arenite sandstone with some amorphous organic matter (dead oil) visible in its pore space. Figure 8c (10,960 ft) displays a medium-grained sandstone with some visible elongated and enlarged secondary porosity, formed by feldspar dissolution at shallow/moderate burial depths. The leached secondary pores commonly contain authigenic kaolinite, organic matter, pyrite, and zircon grains. Figure 8d (10930ft) shows a moderately sorted, medium-grained quartz arenite with visible enlarged secondary intergranular pores containing authigenic kaolinite. The presence of kaolinite partially filling secondary pore spaces in some samples is particularly relevant to formation damage occurring within the Nubian 'C' sandstones (Fig. 8c, d).

Figure 9 displays SEM images from selected Nubian ' $C$ ' core samples from the Sidki-X1 well. They reveal the presence of kaolinite, illite and chlorite within pore spaces that is consistent with the observations from thin-section and XRD sample analysis. The detailed analysis of these images identifies the form and location of the clay minerals within the fabric of the sandstone samples. Fig. 9a $(10,875$ $\mathrm{ft}$ ) shows pore spaces partially filled with clay minerals and some clay overgrowths on quartz grain. The clay mineral in this sample is almost exclusively kaolinite comprised of vermiform booklet crystalline growths. Figure 9b $(10,855$ $\mathrm{ft}$ ) shows illite flakes growing on grain surfaces and also forming quartz overgrowths. Figure 9c (10,965 ft) highlights authigenic clays present within an almost completely leached feldspar grain, formed by clay transformation during acid-water flushing at moderate to deep burial diagenesis. There are platy crystals of illite within the leached secondary porosity and fibrous chlorite coating the surface of the leached grain. Figure 9d (10,935 ft) shows the detailed form of intergranular porosity and identifies that the porosity is reduced predominantly by the presence of clay minerals 

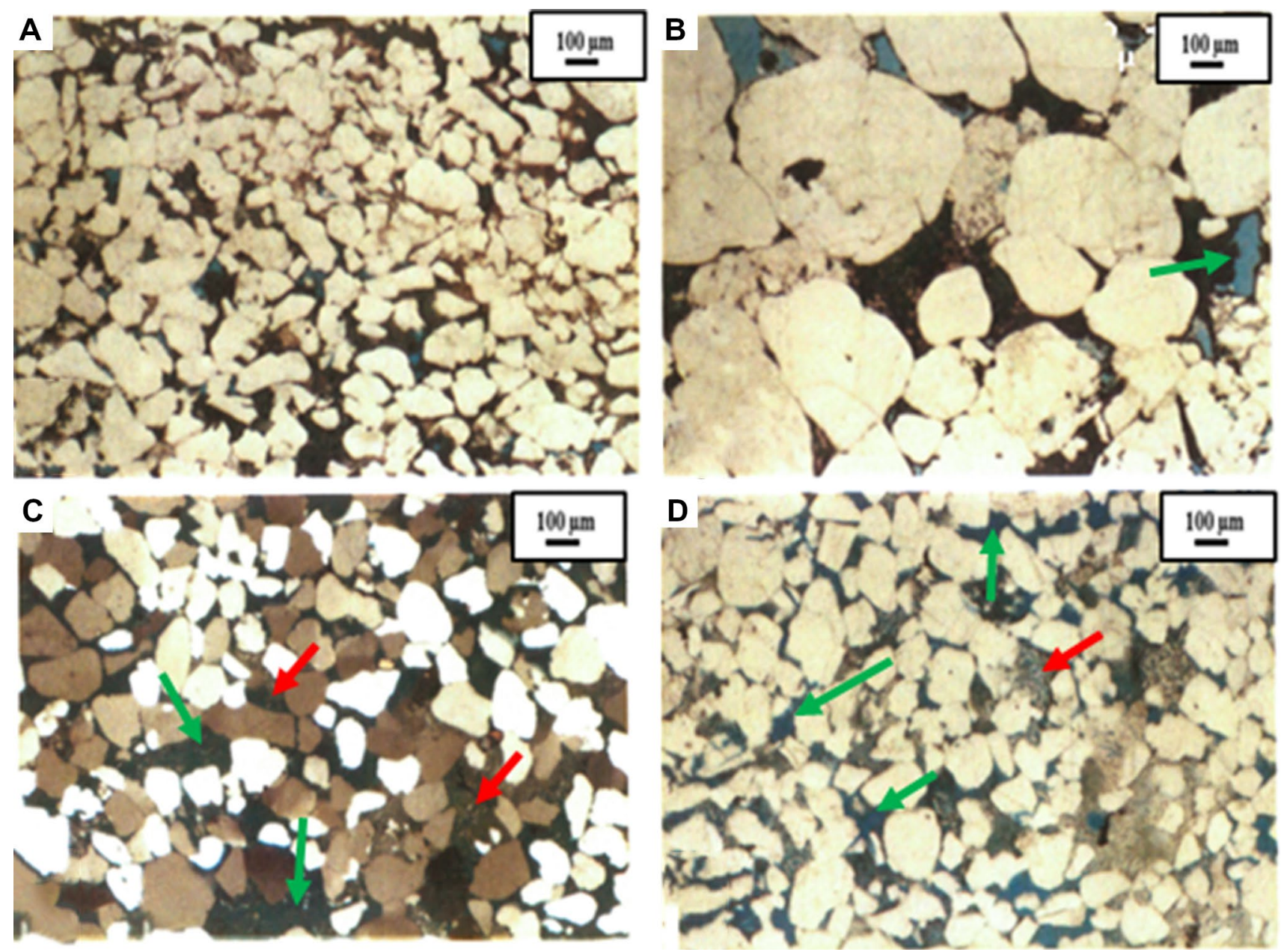

Fig. 8 Thin sections photomicrographs $(30 \times$ magnification $)$ showing the textural details of the Nubian ' $\mathrm{C}$ ' sandstone in Sidki-X1. a Core sample at $10,870 \mathrm{ft}$ in crossed polarized light. b Core sample at $10850 \mathrm{ft}$ in partially crossed polarized light. c Core sample at 10,960

$\mathrm{ft}$ in partially crossed polarized light. d Core sample at $10930 \mathrm{ft}$ in plain polarized light. See text for descriptions of what is displayed in these images. The red arrows identify kaolinite, and the green arrows identify leached secondary porosity

within the pore space. These mineralogical and diagenetic features are consistent with those described from core samples of recovered in other reservoir locations drilled in this field by the Sidki-X2 and Sidki-X3 wells.

\subsubsection{Petrophysical analysis}

The Nubian ' $\mathrm{C}$ ' is characterized by relatively low permeability and porosity compared to the other Nubian units in the basin because of the relatively high abundance of clays and bitumen in the pore spaces [92]. Figure 10 displays the relationship between porosity and permeability, based on Sidki-X1 core sample measurements, for the Nubian ' $C$ ' reservoir zone. The distributions of porosity and permeability across the cored interval of the Nubian ' $C$ ' reservoir reveal fair to good porosity with most samples displaying a range of 0 to $20 \%$ porosity (average is $13 \%$ ); however, some intervals display poor porosity with less than $2 \%$. The permeability

ranges from 0.01 to 40 millidarcy $(\mathrm{mD})$ with an average value of $10(\mathrm{mD})$; however, some intervals display low permeability with less than $1(\mathrm{mD})$. Based on the thin-section point counting about $15-20 \%$ of the Nubia ' $\mathrm{C}$ ' sandstone contained bituminous heavy oil according to Sidki-7 well core analysis. Also, bituminous heavy oil has been recorded in other Sidki field wells. The petrophysical parameters recorded for Sidki-X1 well are consistent with the results of previous analysis of the Nubian sandstone reservoir within the Sidki Field [84].

\subsection{Reservoir Engineering Characterization of the Nubian 'C' Reservoir}

The engineering data available include the initial conditions at the time gas and oil production commenced, fluid production and injection volume history and fluid chemistry. 

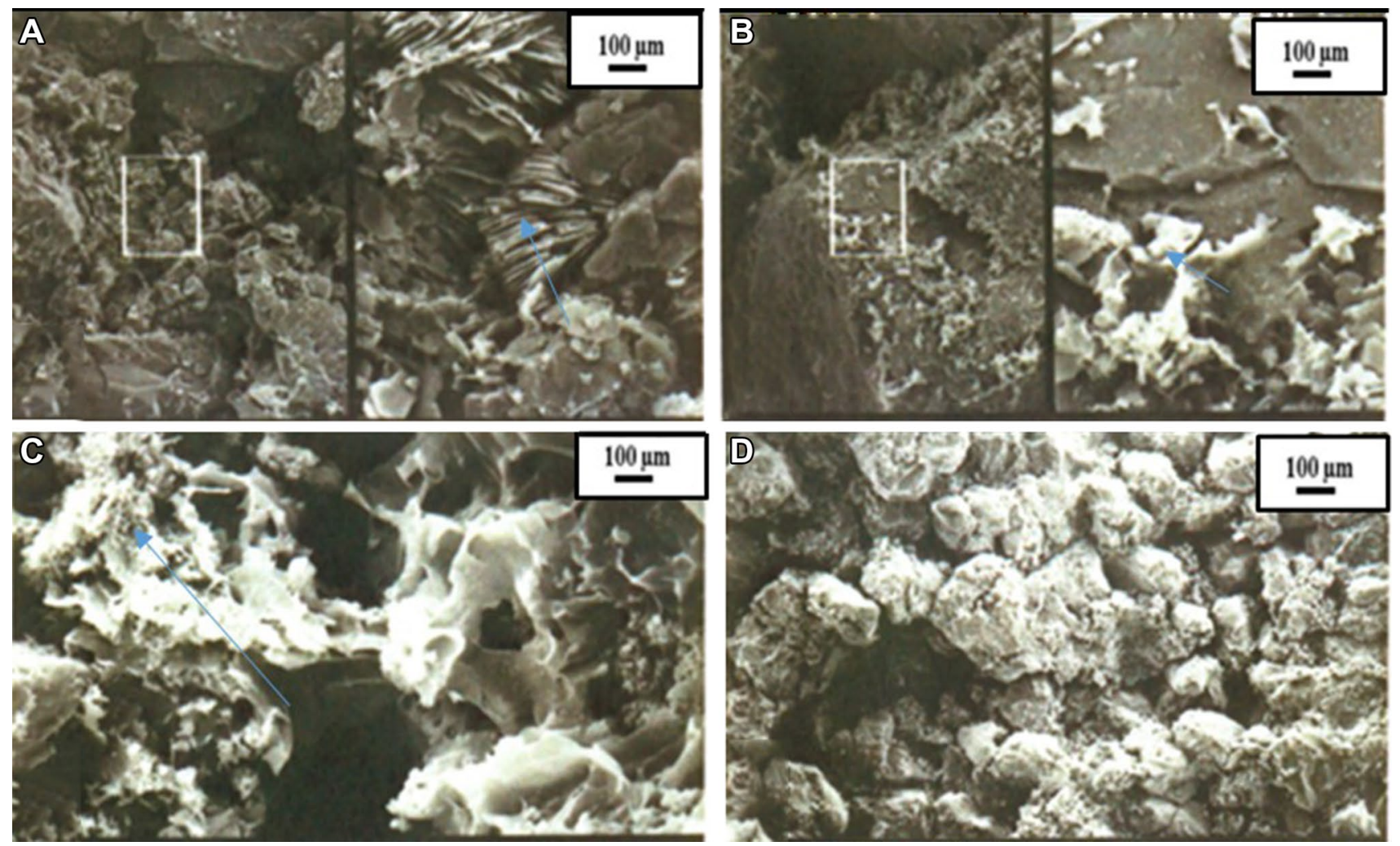

Fig. 9 Scanning electron micrograph images showing the Nubian ' $\mathrm{C}$ ' sandstone minerals at various magnifications. a Core sample at $10,875 \mathrm{ft}$ at $115 \times$ magnification on the left with the inset highlighted area (left) displayed to the right at $575 \times$ magnification. b Core sample at $10,855 \mathrm{ft}$ at $170 \times$ magnification on the left with the inset high-

\subsubsection{Reservoir Conditions}

The Sidki X1 well was completed in the Nubian ' $\mathrm{C}$ ' reservoir as an oil producer with free-flowing gas, and its production was 1902-barrel fluid per day (BFPD) with only $4 \%$ water cut in October 1994. Table 2 summarizes the key Nubian ' $C$ ' reservoir parameters recorded at the Sidki-X1 well. This well penetrated the gas cap, oil leg, and underlying water layers within the Nubian ' $C$ ' reservoir. The initial reservoir pressure was 3020 psi in 1994 and had declined to 1665 psi in 2020 . The well was completed with $130 \mathrm{ft}$ of perforations spread over four intervals in the Nubian ' $C$ ' reservoir (Fig. 6). The reservoir temperature was 232 ${ }^{\circ} \mathrm{F}$ at production startup. The Nubian ' $\mathrm{C}$ ' reservoir became depleted in terms of oil production in 2004 when production had declined to average 300 barrel of oil per day (BOPD). The field reached peak production of 44,000 (BOPD) in 1978 from 2 wells. From 1994 to 2004, the Sidki-X1 well was producing oil.

lighted area (left) displayed to the right at $850 \times$ magnification. $\mathbf{c}$ Core sample $(10,965 \mathrm{ft})$ at $820 \times$ magnification. d Core sample $(10,935 \mathrm{ft})$ at $45 \times$ magnification. See text for descriptions of what is displayed in these images

\subsubsection{Production and Injection History}

All wells in the Sidki field were drilled with the same type and composition of drilling fluid. Initial production rates were very high and none of the wells recorded formation damage at the time of drilling or initial testing and completion [65, 84]. The oil zone intervals (11112-11262ft) penetrated by Sidki-X1 were perforated at the beginning of 1994 and the well commenced production with a flow rate of 1850 BOPD. The well's water cut increased to $12 \%$ at the end of 1994, when another oil interval was perforated (11030-11060ft) and the well's production increased to 1950 BOPD. The water cut progressively increased with time to $84 \%$ and the production decreased to 324 BOPD in 2005. Oil production progressively decreased reaching less than 50 BOPD at the beginning of 2006. Following oil production depletion, the perforations into the depleted oil zones were isolated with cement in June 2006. Subsequently, two gas-bearing intervals were perforated: $10836-10876 \mathrm{ft}$ and 10920-10980ft. and gas production commenced at 8 million standard cubic feet per day (MMSCF) in June 2006. At that time, the bottom hole pressure was 1920 psi. In July 2006, 


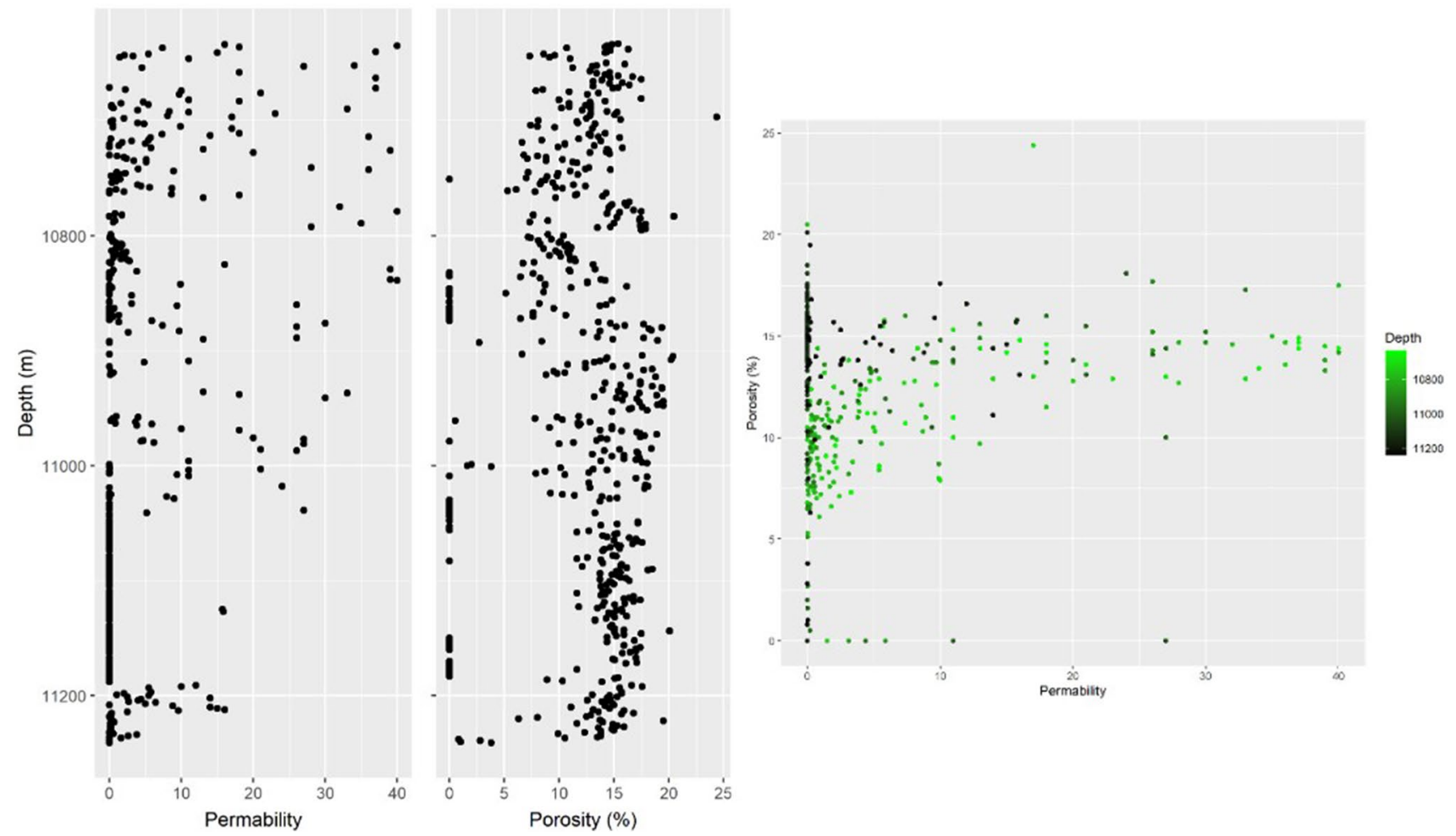

Fig. 10 Porosity versus permeability measurements for the Sidki-X1 well core samples across the depth range 10,870-10,970 ft

Table 2 Reservoir parameters recorded for Nubian 'C' sandstone penetrated by the Sidki-X1 well

\begin{tabular}{lll}
\hline Parameters & Value & Unit \\
\hline Field & Sidki & \\
Well name & SDK-X1 & \\
Well status & Producer & \\
Reservoir & Nubian 'C' & \\
Present reservoir pressure & 1665 & $\mathrm{psi}$ \\
Average water gradient & 0.441 & $\mathrm{psi} / \mathrm{ft}$ \\
Average porosity & 13 & $\%$ \\
Total depth & 11,435 & $\mathrm{ft}$ \\
Reservoir temperature & 232 & $\mathrm{~F}$ \\
Average permeability & 10 & $\mathrm{MD}$ \\
Perforated thickness & 100 & $\mathrm{ft}$ \\
Average API gravity & 21 & $\mathrm{API}$ \\
Initial reservoir pressure & 5340 @ 10,650 ft & $\mathrm{psi}$ \\
& TVDSS & \\
Initial gas to oil ratio (GOR) & 991 & $\mathrm{scf} / \mathrm{stb}$ \\
Last production year & 2004 & \\
\hline
\end{tabular}

a mechanical problem occurred in the production flowline. This caused the Sidki-X1 to be shut-in for a long period. The well was killed using filtered seawater with $4 \% \mathrm{KCl}$ and the fluid density was $8.6 \mathrm{lb}$ per gallon (ppg). The Sidki-X1 well remained shut-in until 2010 when an attempt was made to restart gas production. In July 2010, a recompletion isolated the existing perforations and re-perforated a 130 -ft interval (10836-11180ft) including four separate sets of perforations. However, the well ceased to flow during unloading operations. An acid wash was conducted using a mixture of $\mathrm{HF}$ and acetic acid but this did not stimulate renewed gas flow. The well has remained shut-in since that time (Fig. 11). Scale samples were collected from Sidki-X1 in 2013 during a workover re-entry that tagged the bottom of the well. Analysis of those samples showed that the scale was comprised of $15 \mathrm{wt} \%$ iron sulfide, $35 \mathrm{wt} \%$ calcium carbonate, $40 \mathrm{wt} \%$ chlorides, and $10 \mathrm{wt} \%$ hydrocarbons-based organic scale. Previous studies have previously observed and recovered similar scales in other wells drilled into the Nubian reservoir in many fields in the basin [3-6, 93]. The iron sulfide component of the scale is related to tubing corrosion.

\subsubsection{Reservoir Fluids Analysis}

The Nubian 'C' reservoir was originally drilled by the Sidki$\mathrm{X} 1$ well with $8.9 \mathrm{ppg}$ oil-based drilling fluid. The well completion fluid was $8.6 \mathrm{ppg}$ filtered seawater with $4 \% \mathrm{KCl}$. The acid wash job performed in 2010 pumped 100 barrels into the perforations of a mixture of hydrofluoric acid and acetic acid. Fluid data analysis suggests that the well production problems commenced after the well was killed in 2006 and 


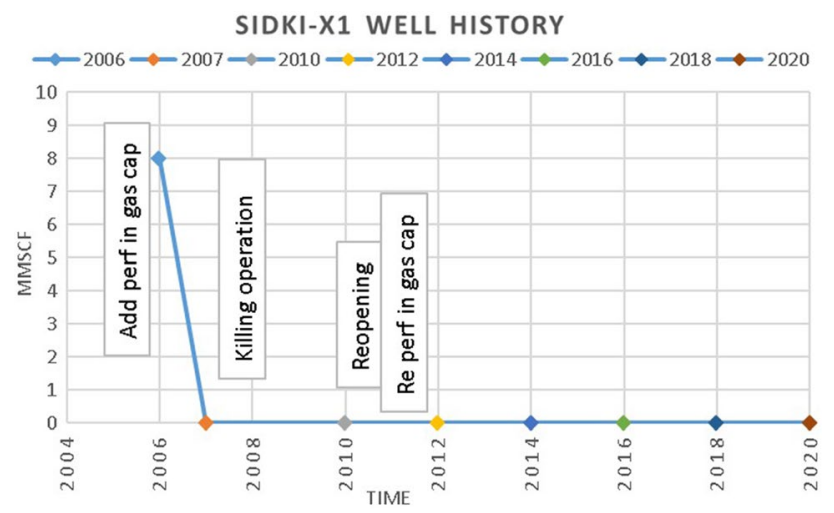

Fig. 11 Production history of Sidki-X1 since it was recompleted as a gas producer in 2006

during the extended shut down period caused by production mechanical problem associated with the production flowline. Unfortunately, this well kill was conducted in highly overbalanced pressure conditions: the kill fluid displayed $8.6 \mathrm{ppg}$ whereas the Nubian ' $C$ ' pore fluid pressure in 2006 (1665 psi) equated to $3 \mathrm{ppg}$. Such over-balanced conditions would have resulted in kill fluid invading the formation through the perforations during the kill operation. Although this type of seawater has been used many times in the Nubian ' $\mathrm{C}$ ' sandstone reservoir in the region, in this instance the kill fluid was left in the Sidki-X1 borehole for a very long time ( $>4$ years). This implies that the filtered seawater completion fluid could be a potential source of formation damage in the Sidki-X1 well. A detailed chemical analysis of the 2006 well kill fluid is displayed and compared with the Sidki-X1 Nubian ' $C$ ' formation water chemistry in Table 3.

The kill fluid exhibits a relatively low salinity but high sulfate concentration compared to the formation water. The formation water in the studied well is matched with the

Table 3 Sidki-X1 2006 kill fluid and reservoir formation water compositions

\begin{tabular}{lll}
\hline Parameters & Kill fluid & Formation water \\
\hline $\mathrm{PH} @ 20{ }^{\circ} \mathrm{C}$ & 7.82 & 5.8 \\
Sp.Gr. @ 20 ${ }^{\circ} \mathrm{C}$ & 1.029 & 1.1 \\
Resistivity @ 20 C & 0.13 & 0.027 \\
CATIONS (ppm) & & \\
$\mathrm{Na}^{+}$ & 13,249 & 45,890 \\
$\mathrm{~K}^{+}$ & 455 & 306 \\
$\mathrm{Ca}^{++}$ & 501 & 1000 \\
$\mathrm{Mg}^{++}$ & 1490 & 10,830 \\
$\mathrm{Sr}^{++}$ & 9 & 116 \\
$\mathrm{Zn}^{++}$ & 1.3 & 23 \\
$\mathrm{ANIONS}(\mathrm{ppm})$ & & \\
$\mathrm{Cl}^{-}$ & 23,393 & 3350 \\
$\mathrm{So}^{-}$ & 110,000 & 110 \\
$\mathrm{HCO}^{-}$ & 230 & 452 \\
\hline
\end{tabular}

regionally formation water in Nubian ' $C$ ' reservoirs in the field. It seems that the formation water composition of Sidki$\mathrm{X} 1$ well has not been significantly impacted by the short water flooding project, as the formation water analysis has remained constant with respect to the analysis of the original formation water in the field recorded prior to production. The injected water was also filtered seawater; filtered for bacteria by adding biocides and by using fine membranes to filter out solids prior to injection.

\section{Discussion}

\subsection{Integrated Analysis of the Available Sidki-X1 Well and Reservoir Data}

Bringing together the results presented in Sect. 4 some important features of the Nubian ' $C$ ' reservoir in the Sidki field stand out.

1. Kaolinite and subordinate illite, according to Civan [18], Radwan [6], and Radwan et al. [3-5], are sensitive minerals that have the potential to become involved in reservoir damage. The presence of significant kaolinite and subordinate illite and chlorite in the reservoir (Fig. 7 and 9), point toward possible formation damage mechanisms because these are sensitive minerals that can be relatively easily altered or mobilized to block some flow channels.

2. The relatively low porosity and permeability of much of the reservoir indicate that relatively minor formation damage could have significant impacts on the fluid flow potential achievable from the reservoir.

3. The pressure depletion and high water cut in the Nubian ' $C$ ' reservoir of the Sidki field following oil depletion had a negative impact on gas flow rates following recompletion to produce gas.

4. The highly over-pressured well kill into the low-pressure reservoir is likely to have involved kill fluid penetrating the perforations into the reservoir leading to formation damage.

5. The contrasting compositions of the kill fluid (low salinity/high sulfate) versus the formation water (high salinity/low sulfate) suggests that fluid incompatibility could have lead to adverse fluid reactions in the reservoir leading to mineral precipitation and/or salinity shock mobilizing clay minerals. In particular, the high content of sulfate in the kill fluid, poses a high risk of precipitating sulfate minerals in the reservoir and contributing to the damage mechanisms.

These factors indicate that multiple formation damage mechanism were potentially triggered and impacting 
the reservoir in the four-year period (2006-2010) that it remained shut-in before the unsuccessful workover (acid wash) operation conducted in 2010. The time of exposure factor has the potential to exacerbate negative formation damage impacts. The longer the exposure time, the more substantial fluid interactions and reactions within the reservoir are likely to be.

Several published studies identify multiple potential causes of formation damage associated with operating practices and equipment associated with well completion and stimulation fluids that are highly relevant to the case study area. These are reviewed in the following paragraphs with an emphasis on the compatibility of the drilling and completion fluids with the formation fluids. Portier et al. [21] and Radwan [6] noted that reservoir damage is often caused by kill fluid invasion and that it typically involves the following processes: (1) Invasion of filtrate into the formation; (2) Invasion of solids into the formation; and (3) Deposition of filter cake in the perforation tunnel. George [94] and Radwan [6] recommended that before selecting a completion or kill fluid composition that it is prudent to check for certain compatibilities. These include (1) compatibility between injected fluids and formation mineralogy, particular the amount and type of clay minerals present; (2) compatibility between injected and formation fluids in terms of the likelihood of their contact leading to the formation of emulsions, sludges, foams and/or froths; and (3) compositions of residual fluids present in surface tanks and equipment, including pumps, flowlines, hoses and blenders, connected to the circulation system. Filtrate and solid contents in kill and completion fluids need to be assessed in terms of fluid compatibility with formation fluids to avoid unwanted reactions and precipitation occurring in the reservoir.

The invasion of completion fluid filtrate and solids into the perforation matrix commonly results in a zone of reduced permeability around the perforation tunnel and the deposition of filter cake in the perforation tunnel and this will partially or completely plug the perforations [1, 8, 21]. The effects of filtrate and solid invasion causing formation damage are well documented, together with recommended methods to mitigate their impacts [95-98]. This issue is associated with drilling fluids as well as kill and completion fluids. The solid particles in drilling fluids also frequently invade reservoirs and plug the pore throats thereby reducing the near-wellbore permeability. Moreover, invading drilling fluid filtrate may interact with the reservoir minerals, particularly clay minerals and cause clay swelling or clay fines migration. Such interactions may alter a reservoir's wettability and in turn the relative permeability of the reservoir fluids, leading to negative impacts on reservoir productivity. Therefore, it is advisable to control both the solid and fluid invasion from well fluids to the formation, commencing at the time of drilling of the formation and continuing through all stimulation and workover operations $[99,100]$. Where, the drilling fluid solids and filtrate invasion are potential candidates and possible sources of initial formation damage [18, 21]. Points 4-5 suggest that in the case of the Sidki-1X well the kill fluid was not only incompatible with the formation fluid, it was also able to penetrate the perforations easily due to the high over-pressured conditions that prevailed during the workover.

Nasr-El-Din et al. [101] and Bedrikovetsky et al. [102] noted that the most severe cases of water blockage are usually associated with low-permeability, low-pressure, gas reservoirs treated with water-based fluids. These are the type conditions in which the Sidki-X1 well stimulation workover was conducted. Therefore, water blockage is one of the relevant mechanism of formation damage likely to be at play in the Sidki reservoir since 2006. The invaded kill fluid has likely plugged key reservoir flow paths preventing gas from flowing. The high capillary pressure in low-permeability reservoirs tends to exacerbate such damage impacts. The water with its high interfacial tension tends to adhere to the rock surface around the wellbore perforations and induces a strong water blockage impact.

\subsection{Formation Damage Diagnosis and Mechanisms Worthy of Consideration}

In the Sidki-X1 well case, based on the integrated assessment of available data, the diagnosis regarding formation damage to Nubian ' $\mathrm{C}$ ' reservoir indicates several potential contributing factors and at least four potential damage mechanisms in play within the reservoir. The factors and mechanisms identified need to be assessed in a coordinated manner. The contributing factors are itemized and discussed in Sect. 5.1. On a balance of probability basis, the damage mechanisms likely to be making variable contributions to formation damage are considered in more detail here.

- Water blockage This involves water, from kill fluid and/ or formation fluid, occupying the flow spaces/channels in the reservoir and thereby reducing the relative permeability of gas. The large contrast between viscosities of water can severely restrict the ability of the gas to displace and penetrate the water blockages and the well ceases to flow in the vicinity of the gas zone perforations. Water blockage occurs more commonly in low-permeability, lowpressure, gas-producing formations due to the increased contribution of high capillary forces drawing water into narrow flow channels $[103,6]$.

- Solid blockage with solids derived from kill/completion fluids Pore channels can become blocked by solids introduced into the reservoir by completion/kill fluids. This may be just filter cake deposition in and around the per- 
foration tunnels but that can have a negative impact on flow, particularly from low-pressure reservoir. The highly over-balanced conditions that prevailed in the 2010 workover operation on Sidki-X1 would be consistent with kill fluids and their associated solids penetrating far beyond the perforations resulting in deep invasion into the reservoir.

- Solid blockage with mobilized authigenic clay minerals Kill/completion fluids invading the reservoir mobilizing fines within the pore space leading to the blockage of some pore throats. Figures 8 and 9 confirm the presence of abundant kaolinite in the secondary pore space of the Sidki-X1 Nubian ' $C$ ' reservoir. It is likely that some of that kaolinite would be mobilized when subjected to kill fluid invasion under highly over-balanced conditions.

- Salinity incompatibility of well and reservoir fluids leading to mineral precipitation The significant salinity difference between 2006-well kill fluid and the formation water, plus the much higher sulfate content of the kill fluid, is likely to have contributed to Nubian ' $\mathrm{C}$ ' formation damage. The significant amount of time that these fluids spent in contact with each other in the near-wellbore zone in static conditions (i.e., 2006 to 2010) may have played a more substantial role with this mechanism. It is likely to have resulted in more extensive precipitation of sulfate minerals in the reservoir than in a situation with flowing conditions restored more quickly following the well kill.

The lessons learned from the integrated assessment of Nubian ' $C$ ' reservoir data for the Sidki-X1 well are the following.

1. There are typically several influencing factors and several mechanisms at play associated with reservoir formation damage. It not usually possible to identify definitively one main cause and one main mechanism.

2. Laboratory compatibility tests of proposed drilling, well kill, completion and/or stimulation fluids and the formation fluids and reservoir rock should be conducted in advance of conducting any downhole operations that have the potential to introduce fluids to the reservoir formation.

3. If cores are available, core flooding tests can be useful in highlighting potential formation damage mechanisms and suggest ways to avoid or mitigate them.

4. Low-pressure/low-permeability gas reservoirs need to be stimulated with care as they are relatively easy to damage with water blockage and other mechanism, which, once induced, is difficult to rectify.

5. Careful filtration of well fluids prior to injection can avoid solid drop out in the perforations and/or reservoir. Solid control in drilling, completion and kill fluids will help to minimize formation damage caused by solids invasion.

6. Thorough cleaning of surface fluid mixing tanks, tubing, and casing is essential steps before any workover operations to ensure that residual materials are not inadvertently picked up by the passing well fluids and introduced into the reservoir.

7. Control the wellbore pressure balance to reduce the fluid invasion. This is difficult in depleted reservoirs but it is better to be underbalanced than overbalanced it terms of the risk of causing formation damage.

8. Long contact time between completion and/or kill fluids and formation water in the borehole or the reservoir is not recommended as it can be exacerbating salt precipitation. This is a particular risk if over-balanced conditions prevail.

From the formation damage mechanisms identified and the lessons learned, it is possible to consider how the 2006 well kill and the 2010 stimulation workover on Sidki-X1 well could have been better designed and implemented. More careful design and preparation of kill fluid and stimulation fluid were clearly required to avoid chemical imbalance with the formation water and the formation clay mineralogy. Additionally, avoiding extreme overbalance conditions during stimulation workovers of this low permeability, low-pressure gas zone would probably have avoided a significant component of the formation damage that actually resulted. More detailed laboratory and core flooding tests were required to establish the most effective stimulation fluid to use in terms of acid volumes and concentrations and the potential benefits of involving a clay stabilizer.

\section{Conclusions}

Integration of field geology, reservoir engineering, production, and fluid data is required to provide a comprehensive assessment of reservoir formation damage risks. Systematically applying an integrated workflow also helps to design reservoir stimulation programs that are most likely to overcome a combination of reservoir damage mechanisms and avoid adding to existing damage. Formation damage analysis of the low-permeability low-pressure Nubian 'C' sandstone reservoir penetrated by the Sidki-X1 integrated detail petrographic, petrophysical, pressure and fluid composition analysis. The analysis identified several key factors contributing to formation damage in this well and at least four damage mechanisms likely to be at play within the reservoir. An incompatibility between kill and stimulation fluids and formation water compositions, highly over-pressured conditions during kill and stimulation operations, high clay contents in the secondary pore space and a long shut-in period were the 
risk key factors contributing to formation damage in this reservoir.

The four formation damage mechanisms identified to be active in the studied reservoir are (1) water blockage; (2) solid invasion of pore channels; (3) deflocculation and mobilization of kaolinite fines leading to blocked pore throats; and (4) salinity shock leading to the deposition of sulfates caused by mixing of incompatible invasion and formation fluids. It is difficult to say with confidence which of these is the dominant mechanism but the low pressure and low permeability of this gas reservoir suggest that it is particularly susceptible to water blockage. Armed with this information remediations treatments can be designed and implemented with more confidence.

Acknowledgements The authors are grateful to the managing editor Prof. Dr. Bassam El Ali and the handling Associate Editor for their effort and time. We are also thankful to the reviewers, for taking the time out to review our submission and provide excellent, detail-oriented reviews. The authors are grateful to the Gulf of Suez Petroleum company and the Egyptian General Petroleum Corporation authorities for providing us the required data and their permissions to carry out this research. Ahmed E. Radwan should refer to the fact that the Polish National Agency for Academic Exchange (NAWA) under project PPN/ ULM/2019/1/00305/U/00001 has facilitated part of this research.

Open Access This article is licensed under a Creative Commons Attribution 4.0 International License, which permits use, sharing, adaptation, distribution and reproduction in any medium or format, as long as you give appropriate credit to the original author(s) and the source, provide a link to the Creative Commons licence, and indicate if changes were made. The images or other third party material in this article are included in the article's Creative Commons licence, unless indicated otherwise in a credit line to the material. If material is not included in the article's Creative Commons licence and your intended use is not permitted by statutory regulation or exceeds the permitted use, you will need to obtain permission directly from the copyright holder. To view a copy of this licence, visit http://creativecommons.org/licenses/by/4.0/.

\section{References}

1. Civan, F.: Reservoir Formation Damage-Fundamentals, Modeling, Assessment, and Mitigation, Gulf Professional Publishing (2007)

2. Hill, D.G.; Lietard, O.M.; Piot, B.M.; King, G.E.: Formation Damage: Origin, Diagnosis and Treatment Strategy. Reservoir Stimulation Book, Third Edition, Chapter 14, John Wiley \& Sons, Ltd (2000)

3. Radwan, A.E.; Abudeif, A.M.; Attia, M.M.; Mahmoud, M.A.: Development of formation damage diagnosis workflow, application on Hammam Faraun reservoir: a case study, Gulf of Suez, Egypt. J. African Earth Sci. 153, 42-53 (2019). https://doi.org/ 10.1016/j.jafrearsci.2019.02.012

4. Radwan, A.E.; Abudeif, A.; Attia, M.; MahmouD, M.: (2019) Development of formation damage diagnosis workflow, application on Hammam Faraun reservoir: a case study, Gulf of Suez, Egypt. In: Offshore Mediterranean Conference. ISBN9788894043679-2019
5. Radwan, A.E.; Abudeif, A.; Attia, M.; MahmouD, M.: (2019). Formation Damage Diagnosis, Application on Hammam Faraun Reservoir: a case study, Gulf of Suez, Egypt. In: Offshore Mediterranean Conference. DOI: https://doi.org/10.13140/RG.2. 2.22352 .66569

6. Radwan, A.E.: Integrated reservoir, geology, and production data for reservoir damage analysis: a case study of the Miocene sandstone reservoir, Gulf of Suez, Egypt. Interpretation 9(4), 1-46 (2021). https://doi.org/10.1190/int-2021-0039.1

7. Clegg, J. D. (2007). Volume IV-Production Operations Engineering. Petroleum Engineering Handbook; Lake, LW, Ed.; Society of Petroleum Engineers: Richardson, TX

8. Civan, F. (2015). Reservoir formation damage: fundamentals, modeling, assessment, and mitigation. Gulf Professional Publishing

9. Yuan, B.; Wood, D. A. (Eds.). (2018). Formation damage during improved oil recovery: Fundamentals and applications. Gulf Professional Publishing 660 pages. ISBN 978-0-12813782-6

10. Yuan, B.; Wood, D.A.: A comprehensive review of formation damage during enhanced oil recovery. J. Petrol. Sci. Eng. 167, 287-299 (2018)

11. Mungan, N. (1989). Discussion of an overview of formation damage. Journal of petroleum technology, 41(11)

12. Priisholm, S.; Nielsen, B.; Haslund, O.: Fines migration, blocking, and clay swelling of potential geothermal sandstone reservoirs, Denmark. SPE Form Eval 2, 168-178 (1987)

13. Ghofrani, R.; Mazeel, A.; Sengupta. P.: (1992) Damage caused by clay-based and clay-free inhibitive fluids in sandstone formations. In: SPE Formation Damage Control Symposium, 1992. Society of Petroleum Engineers

14. Beadie, G. (1995). Well Productivity Awareness School (WPAS) (No. CONF-950533-). Society of Petroleum Engineers, Richardson, TX (United States)

15. Yan, J.; Jiang, G.; Wu, X.: Evaluation of formation damage caused by drilling and completion fluids in horizontal wells. J. Canadian Petrol. Technol. (1997). https://doi.org/10.2118/ 97-05-02

16. Sharma, M.M.; Pang, S.; Wennberg, K.E.; et al.: Injectivity Decline in Water Injection Wells: An Offshore Gulf of Mexico Case Study. Presented at the SPE European Formation Damage Conference, The Hague, The Netherlands, 2-3 June. SPE38180-MS (1997). https://doi.org/10.2118/38180-MS.

17. Doane, R. D.; Bennion, D. B.; Thomas, F. B.; Bietz, R. R.; Bennion, D. W.: Special core analysis designed to minimize formation damage associated with vertical/horizontal drilling applications. J. Canadian Petrol. Technol. 38(05)(1999)

18. Civan, F.: Reservoir Formation Damage: Fundamentals, Modeling, Assessment, and Mitigation, 2nd edn. Gulf Publishing Company, Houston, Texas (2000)

19. Bedrikovetsky, P.; Marchesin, D.; Shecaira, F.; Souza, A.L.; Milanez, P.V.; Rezende, E.: Characterisation of deep bed filtration system from laboratory pressure drop measurements. J. Petrol. Sci. Eng. 32(2-4), 167-177 (2001)

20. Moghadasi, J.; Jamialahmadi, M.; Müller-Steinhagen, H.; Sharif, A.; Izadpanah, M.R.; Motaei, E.; Barati, R.: Formation damage in Iranian oil fields. Society of Petroleum Engineers, In International Symposium and Exhibition on Formation Damage Control (2002)

21. Portier, S.; André, L.; Vuataz, F.D.: Review on chemical stimulation techniques in oil industry and applications to geothermal systems. Engine, work package 4, 32 (2007)

22. Aloui, B.Z.; Gueddari, M.: Long-term water quality monitoring of the Sejnane reservoir in northeast Tunisia. Bull. Eng. Geol. Env. 68(3), 307-316 (2009)

23. Bahrami, H.; Rezaee, R.; Clennell, B.: Water blocking damage in hydraulically fractured tight sand gas reservoirs: an example 
from Perth Basin, Western Australia. J. Petrol. Sci. Eng. 88, 100-106 (2012)

24. El Ela, M.A.: Complete and cost-effective approach for diagnosing formation damage and performing successful stimulation operations. J. Petrol. Sci. Res. 2(2), 65-74 (2013)

25. Wilson, M.J.; Wilson, L.; Patey, I.: The influence of individual clay minerals on formation damage of reservoir sandstones: a critical review with some new insights. Clay Miner. 49(2), 147164 (2014)

26. Mahmoud, M.A.: Evaluating the damage caused by calcium sulfate scale precipitation during low-and high-salinity-water injection. J. Can. Pet. Technol. 53(03), 141-150 (2014)

27. Fang, W.; Jiang, H.; Li, J.; Li, W.; Li, J.; Zhao, L.; Feng, X.: A new experimental methodology to investigate formation damage in clay-bearing reservoirs. J. Petrol. Sci. Eng. 143, 226-234 (2016)

28. Xu, C.; You, Z.; Kang, Y.; You, L.: Stochastic modelling of particulate suspension transport for formation damage prediction in fractured tight reservoir. Fuel 221, 476-490 (2018)

29. Zhao, X.; Qiu, Z.; Sun, B.; Liu, S.; Xing, X.; Wang, M.: Formation damage mechanisms associated with drilling and completion fluids for deepwater reservoirs. J. Petrol. Sci. Eng. 173, 112-121 (2019)

30. Ghasemian, J.; Riahi, S.; Ayatollahi, S.; Mokhtari, R.: Effect of salinity and ion type on formation damage due to inorganic scale deposition and introducing optimum salinity. J. Petrol. Sci. Eng. 177, 270-281 (2019)

31. Wood, D.A.; Yuan, B.: Integrated risks assessment and management of IOR/EOR projects: a formation damage view. Chapter 15 In: Yuan, B.; Wood D.A. (Eds.) Formation Damage During Improved Oil Recovery: Fundamentals and Applications, Pages 587-630. Gulf Publishing (Elsevier) (2018). https://doi.org/10. 1016/B978-0-12-813782-6.00002-6

32. Bennion, D.B.; Thomas, F.B.; Bennion, D.W.; and Beitz, R.F.: Mechanisms of Formation Damage and Permeability Impairment Associated with the Drilling, Completion, and Production of Low Gravity Oil Reservoir. Hycal Energy Research Laboratories LTD, SPE 30320 (2001)

33. Jiao, D.; Sharma, M.M.: Mud induced formation damage in fractured reservoirs. SPE Drill. Complet. 11(01), 11-16 (1996)

34. Del Rio, C.; Boucher, A. R.; Salazar, F.; Milne, A. W.; Robles, M.: Temporary Zonal Isolation Minimizes Reservoir Damage During Workover Operations in Ecuador. In: SPE European Formation Damage Conference. Society of Petroleum Engineers (2011)

35. He, J.; Mohamed, I.M.; Nasr-El-Din, H.A.: Potential Formation Damage Due to Preparing Hcl Acids Using Seawater. Canadian Energy Technol. Innovat. J. 1(4), 56-63 (2013)

36. Bennion, D.B.: An overview of formation damage mechanisms causing a reduction in the productivity and injectivity of oil and gas producing formations. J. Canadian Petrol. Technol. 41(11) (2002)

37. Wu, Y.; Cheng, L.; Huang, S.; Fang, S.; Jia, P.; Rao, X.: An analytical model for analyzing the impact of fracturing fluid-induced formation damage on rate transient behavior in tight formations. J. Petrol. Sci. Eng. 179, 513-525 (2019)

38. Bosworth, W.; Mcclay, K.: Structural and stratigraphic evolution of the Gulf of Suez rift, Egypt: a synthesis. Mémoires du Muséum national d'histoire naturelle 186, 567-606 (2001)

39. Alsharhan, A.S.: Petroleum geology and potential hydrocarbon plays in the Gulf of Suez rift basin Egypt. AAPG bulletin 87(1), 143-180 (2003)

40. Attia, M.; Abudeif, A.; Radwan, A.: Petrophysical analysis and hydrocarbon potentialities of the untested Middle Miocene Sidri and Baba sandstone of Belayim Formation, Badri field, Gulf of
Suez, Egypt. J. Afr. Earth Sci. 109, 120-130 (2015). https://doi. org/10.1016/j.jafrearsci.2015.05.020

41. Abudeif, A.; Attia, M.; Radwan, A.: New simulation technique to estimate the hydrocarbon type for the two untested members of Belayim Formation in the absence of pressure data, Badri Field, Gulf of Suez, Egypt. Arabian J. Geosci. 9, 218 (2016). https:// doi.org/10.1007/s12517-015-2082-2

42. Abudeif, A.; Attia, M.; Radwan, A.: Petrophysical and petrographic evaluation of Sidri Member of Belayim Formation, Badri field, Gulf of Suez, Egypt. J. Afr. Earth Sci. 115, 108-120 (2016). https://doi.org/10.1016/j.jafrearsci.2015.11.028

43. Abudeif, A.M.; Attia, M.M.; Al-Khashab, H.M.; Radwan, A.E.: Hydrocarbon type detection using the synthetic logs: a case study, Baba member, Gulf of Suez, Egypt. J. Afr. Earth Sci. 144, 176-182 (2018). https://doi.org/10.1016/j.jafrearsci.2018.04.017

44. Radwan, A.E.: New petrophysical approach and study of the pore pressure and formation damage in Badri, Morgan and Sidki fields, Gulf of Suez Region Egypt: PhD Thesis (2018). https:// doi.org/10.13140/RG.2.2.26651.82727

45. Radwan, A.E.: Petrophysical evaluation for Sidri and Baba members within Belayim Formation in the region of Badri field, Gulf of Suez, Egypt. M.Sc. Thesis (2014). https://doi.org/10.13140/ RG.2.2.22772.09601

46. Afifi, A.S.; Moustafa, A.R.; Helmy, H.M.: Fault block rotation and footwall erosion in the southern Suez rift: implications for hydrocarbon exploration. Mar. Pet. Geol. 76, 377-396 (2016)

47. Radwan, A.E.; Abudeif, A.M.; Attia, M.M.; Mohammed, M.A.: Pore and fracture pressure modeling using direct and indirect methods in Badri Field, Gulf of Suez, Egypt. J. African Earth Sci. 156, 133-143 (2019). https://doi.org/10.1016/j.jafrearsci. 2019.04.015

48. Kassem, A.A.; Hussein, W.S.; Radwan, A.E.; Anani, N.; Abioui, M.; Jain, S.; Shehata, A.A.: Petrographic and diagenetic study of siliciclastic jurassic sediments from the northeastern margin of Africa: implication for reservoir quality. J. Petrol. Sci. Eng. (2021). https://doi.org/10.1016/j.petrol.2020.108340

49. Kassem, A.A.; Sen, S.; Radwan, A.E.; et al.: Effect of depletion and fluid injection in the mesozoic and paleozoic sandstone reservoirs of the october oil field, Central Gulf of Suez Basin: implications on drilling, production and reservoir stability. Nat Resour. Res. (2021). https://doi.org/10.1007/s11053-021-09830-8

50. Radwan, A.E.; Abudeif, A.M.; Attia, M.M.; Elkhawaga, M.A.; Abdelghany, W.K.; Kasem, A.A.: Geopressure evaluation using integrated basin modelling, well-logging and reservoir data analysis in the northern part of the Badri oil field, Gulf of Suez, Egypt. J. African Earth Sci. 162, 103743 (2020). https://doi.org/ 10.1016/j.jafrearsci.2019.103743

51. Radwan, A.E.; Kassem, A.A.; Kassem, A.: Radwany formation: a new formation name for the early-middle eocene carbonate sediments of the offshore october oil field, Gulf of Suez: contribution to the eocene sediments in Egypt. Mar. Pet. Geol. 116, 104304 (2020). https://doi.org/10.1016/j.marpetgeo.2020.104304

52. Radwan, A.E.; Abudeif, A.M.; Attia, M.M.: Investigative petrophysical fingerprint technique using conventional and synthetic logs in siliciclastic reservoirs: A case study, Gulf of Suez basin, Egypt. J. Afr. Earth Sci. 167, 103868 (2020). https://doi.org/10. 1016/j.jafrearsci.2020.103868

53. Abdelghany, W.K.; Radwan, A.E.; Elkhawaga, M.A.; Wood, D.; Sen, S.; Kassem, A.A.: Geomechanical modeling using the depth-of-damage approach to achieve successful underbalanced drilling in the Gulf of Suez Rift Basin. J. Petrol. Sci. Eng. (2021). https://doi.org/10.1016/j.petrol.2020.108311

54. Radwan, A.E.; Trippetta, F.; Kassem, A.A.; Kania, M.: Multiscale characterization of unconventional tight carbonate reservoir: Insights from October oil filed, Gulf of Suez rift basin, 
Egypt. J. Petrol. Sci. Eng. (2021). https://doi.org/10.1016/j.petrol.2020.107968

55. Radwan, A.E.; Nabawy, B.S.; Kassem, A.A.; et al.: Implementation of rock typing on waterflooding process during secondary recovery in oil reservoirs: a case study, El Morgan Oil Field, Gulf of Suez, Egypt. Nat. Resour. Res. (2021). https://doi.org/10.1007/ s11053-020-09806-0

56. Radwan, A.E.; Rohais, S.; Chiarella, D.: Combined stratigraphicstructural play characterization in hydrocarbon exploration: a case study of Middle Miocene sandstones, Gulf of Suez basin. Egypt. J. Asian Earth Sci. (2021). https://doi.org/10.1016/j.jseaes.2021.104686

57. Radwan, A.E.; Abdelghany, W.K.; Abdelghany, W.K.: Presentday in-situ stresses in Southern Gulf of Suez, Egypt: Insights for stress rotation in an extensional rift basin. J. Struct. Geol. (2021). https://doi.org/10.1016/j.jsg.2021.104334

58. Radwan, A.E.: Modeling the depositional environment of the sandstone reservoir in the middle miocene sidri member, Badri Field, Gulf of Suez Basin, Egypt: Integration of Gamma-Ray Log patterns and petrographic characteristics of lithology. Nat. Resour. Res. 30, 431-449 (2021). https://doi.org/10.1007/ s11053-020-09757-6

59. Radwan, A.E.: Modeling pore pressure and fracture pressure using integrated well logging, drilling based interpretations and reservoir data in the Giant El Morgan oil Field, Gulf of Suez, Egypt. J. African Earth Sci. (2021). https://doi.org/10. 1016/j.jafrearsci.2021.104165

60. Radwan, A.; Sen, S.: Stress path analysis for characterization of in situ stress state and effect of reservoir depletion on present-day stress magnitudes: reservoir geomechanical modeling in the Gulf of Suez Rift Basin, Egypt. Nat. Resour. Res. 30(1), 463-478 (2021). https://doi.org/10.1007/s11053-020-09731-2

61. Radwan, A.E.; Sen, S.: Characterization of in-situ stresses and its implications for production and reservoir stability in the depleted El Morgan hydrocarbon field Gulf of Suez Rift Basin, Egypt. J. Struct. Geol. 148, 104355 (2021). https://doi.org/10. 1016/j.jsg.2021.10435510.1016/j.jsg.2021.104355

62. Ezzat, A.M.; Clark, T.J.: Redeveloping the Sidki Field: how on company turned an accident into an opportunity, Proceedings 13th Exploration \& Production Conference, Cairo: EGPC. Production 1, 175-191 (1996)

63. Ezzat, A.M.; Clark, T.J.: Redeveloping the Sidki Field: how on company turned an accident into an opportunity, Proceedings SPE European Petroleum Conference, Milan, p. 61-69: SPE Paper 36897 (1996)

64. Helmy, H.M.: Southern Gulf of Suez, Egypt: structural geology of the B-trend oil fields. Geol. Soc., London, Special Publications 50(1), 353-363 (1990)

65. EGPC: Gulf of Suez oil fields (a comprehensive overview): Egyptian General Petroleum Corporation, Cairo, 736pp (1996)

66. Pettijohn, F.J.: Classification of sandstones. J. Geol. 62(4), 360-365 (1954)

67. Dott Jr, R.H.: Wacke, Graywacke and Matrix--What Approach to Immature Sandstone Classification?. J. Sedimentary Res. 34(3) (1964)

68. Folk, R.L.: Petrology of Sedimentary Rocks: Austin, p. 182. Hemphill Press, second edition, TX (1974)

69. Patchett, J. G.; Coalson, E.B.: The Determination Of Porosity In Sandstone And Shaly Sandstone Part Two-Effects Of Complex Mineralogy And Hydrocarbons. In SPWLA 23rd Annual Logging Symposium. Society of Petrophysicists and Well-Log Analysts (1982)

70. Poupon, A.; Hoyle, W.R.; Schmidt, A.W.: Log analysis in formations with complex lithologies. J. Petrol. Technol. 23(08), 995-1001 (1971)
71. Suau, J.; Spurlin, J.: Interpretation of micaceous sandstones in the North Sea. In SPWLA 23rd Annual Logging Symposium. Society of Petrophysicists and Well-Log Analysts (1982)

72. Radwan, A.E.: Wellbore stability analysis and pore pressure study in Badri field using limited data, Gulf of Suez, Egypt: AAPG/Datapages Search and Discovery Article \#20476 (2020a).https://doi.org/10.1306/20476Radwan2020

73. Radwan, A.E.: Hydrocarbon Type Estimation Using the Synthetic Logs: A Case Study in Baba Member, Gulf of Suez, Egypt: AAPG/Datapages Search and Discovery Article \#20475 (2020b). https://doi.org/10.1306/20475Radwan2020.

74. Radwan, A.E.: Effect of Clay Minerals in Oil and Gas Formation Damage Problems and Production Decline: A Case Study, Gulf of Suez, Egypt: AAPG/Datapages Search and Discovery Article \#20477 (2020c). https://doi.org/10.1306/20477Radwan2020

75. Shehata, A.A.; Kassem, A.A.; Brooks, H.L.; Zuchuat, V.; Radwan, A.E.: Facies analysis and sequence-stratigraphic control on reservoir architecture: Example from mixed carbonate/siliciclastic sediments of Raha Formation, Gulf of Suez, Egypt. Mar. Pet. Geol. 131, 105160 (2021). https://doi.org/10.1016/j.marpetgeo. 2021.105160

76. Du Bernard, X.; Carrio-Schaffhauser, E.: Kaolinitic meniscus bridges as an indicator of early diagenesis in Nubian sandstones, Sinai, Egypt. Sedimentology 50(6), 1221-1229 (2003)

77. Ketzer, J.M.; De Ros, L.F.; Dani, N.: Kaolinitic meniscus bridges as an indicator of early diagenesis in Nubian sandstones, Sinai, Egypt-discussion. Sedimentology 52(1), 213-217 (2005)

78. Alsharhan, A.S.; Salah, M.G.: Lithostratigraphy, sedimentology and hydrocarbon habitat of the pre-Cenomanian Nubian ' $C$ ' Sandstone in the Gulf of Suez Oil Province. Egypt. GeoArabia 2(4), 385-400 (1997)

79. Kassab, M.A.; Hassanain, I.M.; Salem, A.M.: Petrography, diagenesis and reservoir characteristics of the pre-Cenomanian sandstone, Sheikh Attia area, East Central Sinai. Egypt. J. Afr. Earth Sci. 96, 122-138 (2014)

80. Elgendy, N.T.; Abuamarah, B.A.; Nabawy, B.S.; Ghrefat, H.; Kassem, O.M.: Pore fabric anisotropy of the Cambrian-Ordovician Nubia sandstone in the Onshore Gulf of Suez, Egypt: a surface outcrop analog. Nat. Resour. Res. 29(2), 1307-1328 (2020)

81. Moustafa, A. R.: Explanatory notes for the geologic maps of the eastern side of the Suez Rift (western Sinai Peninsula): Cairo, Egypt, AAPG/Datapages GIS Series, 34 p (2003)

82. Nabawy, B.S.; Géraud, Y.; Rochette, P.; Bur, N.: Pore-throat characterization in highly porous and permeable sandstones. AAPG Bull. 93(6), 719-739 (2009)

83. Torabi, A.; Fossen, H.: Spatial variation of microstructure and petrophysical properties along deformation bands in reservoir sandstones: AAPG Bulletin. vol. 93, pp. 919-938 (2009). https:// doi.org/10.1306/03270908161

84. Gameel, M.; Darwish, M.: Reservoir behaviour of the pre-Turonian sandstones in south Gulf of Suez province (Sidki Field-case history): proceedings 12th exploration \& production conference, cairo: EGPC. Exploration 2, 449-471 (1994)

85. Aweny, F.: Petrophysics and reservoir geology of the Nubia 'C' Sandstone of the Ramadan and July oil fields, in Hantar, G. ed, Proceedings 6th Petroleum Exploration Seminar: EGPC Exploration vol. 1, pp. 310-330 (1982)

86. Sellwood, B.W.; Netherwood, R.E.: Facies evolution in the Gulf of Suez area: sedimentation history as an indicator of rift initiation and development: Modern Geology, vol. 9, pp. 43-69 (1984)

87. Lelek, J.J.; Shepherd, D.B.; Stone, D.M.; Abdine, A.S.: October Field - the latest giant under development in Egypt's Gulf of Suez, in Halbouty, M.T., ed., Giant Oil and Gas Fields of the Decade 1978- 1988: AAPG Memoir, no. 54, pp. 231-249 (1992)

88. Blatt, H.: Diagenetic processes in sandstones (1979) 
89. Aplin, A.C.; Warren, E.A.; Grant, S.M.; Robinson, A.G.: Mechanisms of Quartz Cementation in North Sea Reservoir Sandstones: Constraints from Fluid Compositions: Chapter 2: constraints on diagenetic processes (1993)

90. Vásárhelyi, B.: Some observations regarding the strength and deformability of sandstones in dry and saturated conditions. Bull. Eng. Geol. Env. 62(3), 245-249 (2003)

91. Li, Y.; Chang, X.; Yin, W.; Sun, T.; Song, T.: Quantitative impact of diagenesis on reservoir quality of the Triassic Chang 6 tight oil sandstones, Zhenjing area, Ordos Basin, China. Mar. Pet. Geol. 86, 1014-1028 (2017)

92. Macary, S. M.: Conversion of air permeability to liquid permeabilities extracts huge source of information for reservoir studies. In: Middle East Oil Show and Conference. Society of Petroleum Engineers (1999\}

93. El-Hattab, M.I.: Scale deposition in surface and subsurface production equipment in the Gulf of Suez. J. Petrol. Technol. 37(09), 1-640 (1985)

94. George E. King, P.E.: Acidizing - Causes of Failures. Halliburton, Carbonate Matrix Acidizing Treatments, Best Practices Series (2014)

95. Hemeida, A. M.; Gawish, A.A.: Formation Damage Tests of Some Completion Fluids.Oil and Gas Business (2008). http:// www.ogbus.ru/eng. https://pdfs.semanticscholar.org/2f47/bfb53 a7612a94b4ad9ab9b3c4da632f045b6.pdf

96. Elkatatny, S.; Mahmoud, M.A.; Nasr-El-Din, H.A.: Characterization of filter cake generated by water-based drilling fluids using CT scan. SPE Drill. Complet. 27(02), 282-293 (2012)
97. Bahrami, H.; Rezaee, R.; Nazhat, D.; Ostojic, J.: Evaluation of damage mechanisms and skin factor in tight gas reservoirs. The APPEA Journal 51(1), 639-652 (2011)

98. Zhao, X.; Qiu, Z.; Huang, W.; Wang, M.: Mechanism and method for controlling low-temperature rheology of water-based drilling fluids in deep water drilling. J. Petrol. Sci. Eng. 154, 405-416 (2017)

99. Thomas, R.L.; Morgenthaler, L.N.: In: Economics, M.J., Notle, K.G. (Eds.) Introduction to Matrix Stimulation in Reservoir Stimulations, third ed. John Wiley \& Sons, Chichcester (2000)

100. Yang, S.; Sheng, Z.; Liu, W.; Song, Z.; Wu, M.; Zhang, J.: Evaluation and prevention of formation damage in offshore sandstone reservoirs in China. Pet. Sci. 5(4), 340-347 (2008)

101. Nasr-El-Din, H.A.; Lynn, J.D.; Al-Dossary, K.A.: Formation damage caused by a water blockage chemical: prevention through operator supported test programs. Society of Petroleum Engineers, In International Symposium and Exhibition on Formation Damage Control (2002)

102. Bedrikovetsky, P.G.; Da Silva, M.J.; Rocha Fonseca, D.; Da Silva, M.F.; Siqueira, A.G.; de Souza, A.L.; Furtado, C.J.A.: Well-history-based prediction of injectivity decline during seawater flooding. In: SPE European Formation Damage Conference. Society of Petroleum Engineers (2005)

103. Bennion, D.B.; Thomas, F.B.: Formation damage issues impacting the productivity of low permeability, low initial water saturation gas producing formations (2005) 